\title{
Smelling, Tasting, Learning: Drosophila as a Study Case
}

\author{
B. Gerber, R.F. Stocker, T. Tanimura, and A.S. Thum
}

\begin{abstract}
Understanding brain function is to account for how the sensory system is integrated with the organism's needs to organize behaviour. We review what is known about these processes with regard to chemosensation and chemosensory learning in Drosophila. We stress that taste and olfaction are organized rather differently. Given that, e.g., sugars are nutrients and should be eaten (irrespective of the kind of sugar) and that toxic substances should be avoided (regardless of the kind of death they eventually cause), tastants are classified into relatively few behavioural matters of concern. In contrast, what needs to be done in response to odours is less evolutionarily determined. Thus, discrimination ability is warranted between different kinds of olfactory input, as any difference between odours may potentially be or become important. Therefore, the olfactory system has a higher dimensionality than gustation, and allows for more sensory-motor flexibility to attach acquired behavioural 'meaning' to odours. We argue that, by and large, larval and adult Drosophila are similar in these kinds of architecture, and that additionally there are a number of similarities to vertebrates, in particular regarding the cellular architecture of the olfactory pathway, the functional slant of the taste and smell systems towards classification versus discrimination, respectively, and the higher plasticity of the olfactory sensory-motor system. From our point of view, the greatest gap in understanding smell and taste systems to date is not on the sensory side, where indeed impressive advances have been achieved; also, a satisfying account of associative odour-taste memory trace formation seems within reach. Rather, we lack an understanding as to how sensory and motor formats of processing are centrally integrated, and how adaptive motor patterns actually are selected. Such an understanding, we believe, will allow the analysis to be extended to the motivating factors of behaviour, eventually leading to a comprehensive account of those systems which make Drosophila do what Drosophila's got to do.
\end{abstract}

\footnotetext{
B. Gerber ( $)$

Universität Würzburg, Biozentrum, Am Hubland, 97074 Würzburg, Germany

e-mail: bertram.gerber@biozentrum.uni-wuerzburg.de
} 


\section{Introduction}

There are more things in the world than there are possible behaviours. Thus, in order to fulfil the needs of life, the things in the outside world need to be 'funnelled' into far fewer behavioural matters of concern. Integrating the sensory system with the biological needs to come up with appropriate behaviour is what brains have evolved for. It is this triad of things, needs and actions that neurobiology needs to understand.

Notably, it cannot be known in advance which sensory-motor match would be the most fitting one; thus, both during evolution and during learning, possible matches need to be tried out, by taking chances, and the ones with the relatively best fit are stabilized. As a study case, we focus on the functional architecture of the fruit fly chemosensory-motor system to see with which kind of circuitry these problems have evolutionarily been solved regarding smell and taste. We then move on to chemosensory associative learning, to see which degrees of freedom remain for the individual to seize upon the opportunities, and cope with the perils, of life.

Taste is more closely entangled with immediate behaviour control than olfaction. That is, the behavioural 'meaning' of tastants is evolutionarily obvious, in that, for example, energy-rich foods should be eaten and toxic substances should be avoided. Accordingly, tastants seem to be classified into relatively few behavioural matters of concern (edible/sweet, non-edible/bitter, to mention two of them), leaving largely superfluous discrimination between, e.g., different kinds of sweetness. In contrast, it seems much less obvious how to behave towards a given odour. This not only requires flexibility in the sensory-motor 'switchboard', but also requires the ability to discriminate between as many different odours as possible. This has two corollaries, namely that the olfactory system has a higher dimensionality on the sensory side, and that it possesses a dedicated subsystem which allows acquired behavioural 'meaning' to be attached to them. Owing to its cellular simplicity and genetic accessibility, the fruit fly Drosophila is a suitable study case to understand how these processes come about.

\section{Smelling}

Olfactory systems help to track down matters of concern, such as food sources, shelters, oviposition sites or social interaction partners. How does this work in a fly? (For classical accounts see Rodrigues and Siddiqi 1978 and Rodrigues 1980.) Are the mechanisms similar to those in mice or in humans? Indeed, there are surprising parallels between these phylogenetically distant kinds of animal (Ache and Young 2005; Hildebrand and Shepherd 1997; Strausfeld and Hildebrand 1999). These similarities do not necessarily postulate a common origin of olfactory systems, however; rather, to the extent that these systems are not of common origin, similarities and discrepancies between them point to common versus specific functional demands of olfactory systems in different animals. 
Common to both phyla is that odorants need to travel through an extracellular matrix ('lymph' in insects) to the olfactory receptor neurons (ORNs). Their dendritic membranes carry olfactory receptor proteins (ORs), which determine the spectrum of odours that can activate the cell. Similar is also that all and only those cells that express the same OR converge in one spherical 'glomerulus' structure in the primary olfactory centre (called 'olfactory bulb' in vertebrates and 'antennal lobe' in insects) (Fig. 1). Lateral connections between the glomeruli contribute to the establishment of specific patterns of activated glomeruli for each particular odour. For further processing, output neurons typically sample one glomerulus each and establish divergent, combinatorial connections to higher-order brain centres. Such architecture seems suitable to achieve both a good signal-to-noise ratio (convergence) and high discriminability (combinatorial divergence). Higher centres thus appear to increase the distinctiveness of 'odour images', and in addition act as a switchboard to refer different odours to distinct behavioural programmes. In other words, they act as a 'watershed' along the sensory-motor pathway, transforming olfactory information ('Which odour?') into motor commands ('What should be done?'). However, this reformatting and in particular the premotor processes themselves are poorly understood. What seems plausible is that the pathways underlying innate behaviour are simpler, more direct and certainly more stereotypic than those which mediate learning-related changes.

\subsection{Olfactory Organs of Adult Drosophila}

While mammalian ORNs are densely clustered in an epithelium deep inside the nose, in insects one to four ORNs are housed in hairlike structures on the body surface, called 'sensilla' (Fig. 2). The dendrites of the ORNs, expressing the ORs, extend into the lymph of the sensillum shaft. At least for certain pheromones, ORN activation requires the presence of an odorant-binding protein in the lymph (Ha and Smith 2006). The stereotyped assembly of ORNs in sensilla has proven useful to record from identified neurons and to define the range of odours to which they respond.

Olfactory sensilla of Drosophila are located at two sites, the third antennal segment and the maxillary palp (Fig. 1). The palp carries approximately 60 morphologically uniform basiconic sensilla, each housing two ORNs. These ORNs fall into six different functional classes with respect to their odour spectra (de Bruyne et al. 1999) reflecting different combinations of expressed ORs (Couto et al. 2005; Goldman et al. 2005). The third antennal segment is covered by three major morphological types of sensilla - basiconic, trichoid and coeloconic - each comprising several subtypes (Shanbhag et al. 1999) (Fig. 2). Every subtype is found in a specific spatial arrangement on the antenna. Trichoid and basiconic sensilla are sexually dimorphic in number, with $30 \%$ more trichoids and $20 \%$ fewer basiconics in males than in females (Stocker 1994). Antennal basiconic sensilla house two or four neurons, trichoid sensilla house one, two or three neurons and coeloconic sensilla house two or three neurons (Shanbhag et al. 1999). For the majority of antennal ORNs from all of these sensilla types, ligand ranges have been determined 

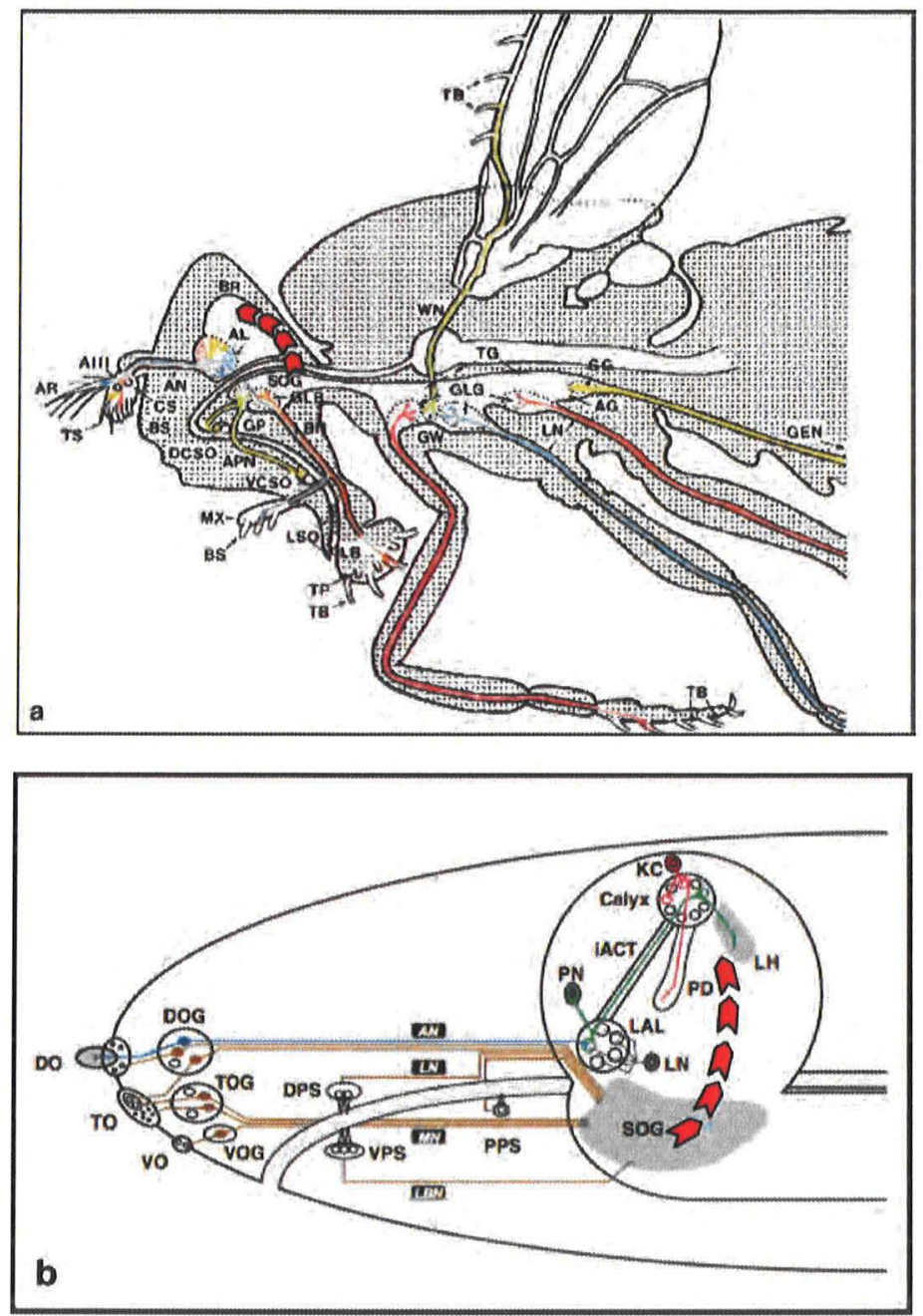

Fig. 1 Overview of the Drosophila chemosensory system. a Overview of the adult chemosensory pathways. Olfactory pathways project to the brain proper, whereas gustatory afferents are collected in various regions of the suboesophageal and thoracic ganglion. The chevrons indicate the proposed pathway to short-circuit a taste-driven reward signal carried by octopaminergic neurons from the suboesophageal ganglion towards the brain. b Overview of the larval chemosensory pathways. As in adults, olfactory pathways project into the brain proper, whereas gustatory afferents are collected in various regions of the suboesophageal ganglion. The chevrons have the same meaning as in a. c Scanning electron microscopy (SEM) overview of the larval head. One can discern the domeshaped dorsal organ, and the wart-like terminal organ. The cirri surround the mouth opening (triangle) and, in the third row of cirri, cover the tiny ventral organ. d SEM overview of the adult head and appendages in labellum-opened state. Medial from the large complex eyes, one can discern the arista and the third antennal segment, as well as the maxillary palps and the labellum. e Comparison of the approximate number of, from left to right, olfactory receptor neurons, antennal lobe glomeruli, projection neurons, calycal glomeruli in the mushroom bodies and mushroom body Kenyon cells. Note that the local interneurons in the antennal lobe, which shape olfactory activity, are present in both larva and adult, but are omitted in this figure. AIII third antennal 

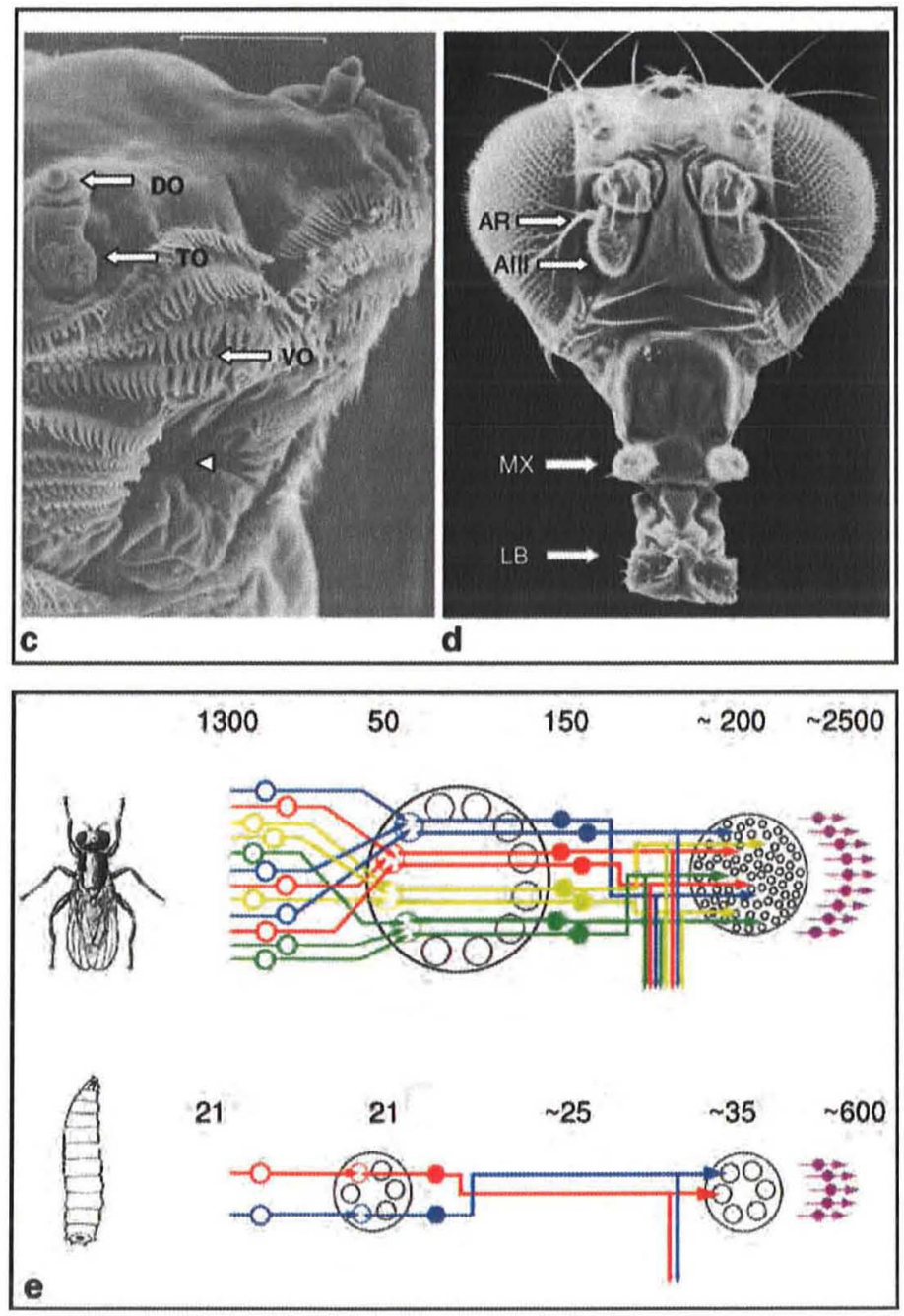

Fig. 1 (continued) segment, AR arista, AL antennal lobe, $A N$ antennal nerve, APN accessory pharyngeal nerve, BR brain, BS basiconic sensilla, CS coeloconic sensilla, DO dorsal organ, DOG dorsal organ ganglion, DPS dorsal pharyngeal sense organ, DCSO dorsal cibarial sense organ, GEN genitalia, GG gustatory centre of genitalia, GLB gustatory centre of the labellum, GLG gustatory centres of the leg, GP gustatory centre of the pharynx, GW gustatory centre of the wing, iACT inner antennocerebral tract, KC Kenyon cells, LAL larval antennal lobe, LB labellum (labial palps), $L B N$ labial nerve, LH lateral horn, LN local interneurons, $L N$ labral nerve, LSO labra sense organ, $M N$ maxillary nerve, MX maxillary palp, PD pedunculus, PN projection neuron, PPS posterior pharyngeal sense organ, SOG suboesophageal ganglion, TO terminal organ, TOG terminal organ ganglion, TB taste bristle, TG thoracic ganglion, TP taste peg, TS trichoid sensilla, VCSO ventral cibarial sense organ, VO ventral organ, VOG ventral organ ganglion, VPS ventral pharyngeal sense organ, WN wing nerve. (a From Stocker 1994, copyright Springer. b From Stocker 2006, copyright Landes Bioscience. c Copyright K. Neuser, Universität Würzburg. d From "The Interactive Fly", http://www.sdbonline.org/fly/aimain/1aahome.htm", copyright F.R. Turner, Indiana University. e From Ramaekers et al. 2005, copyright Elsevier) 

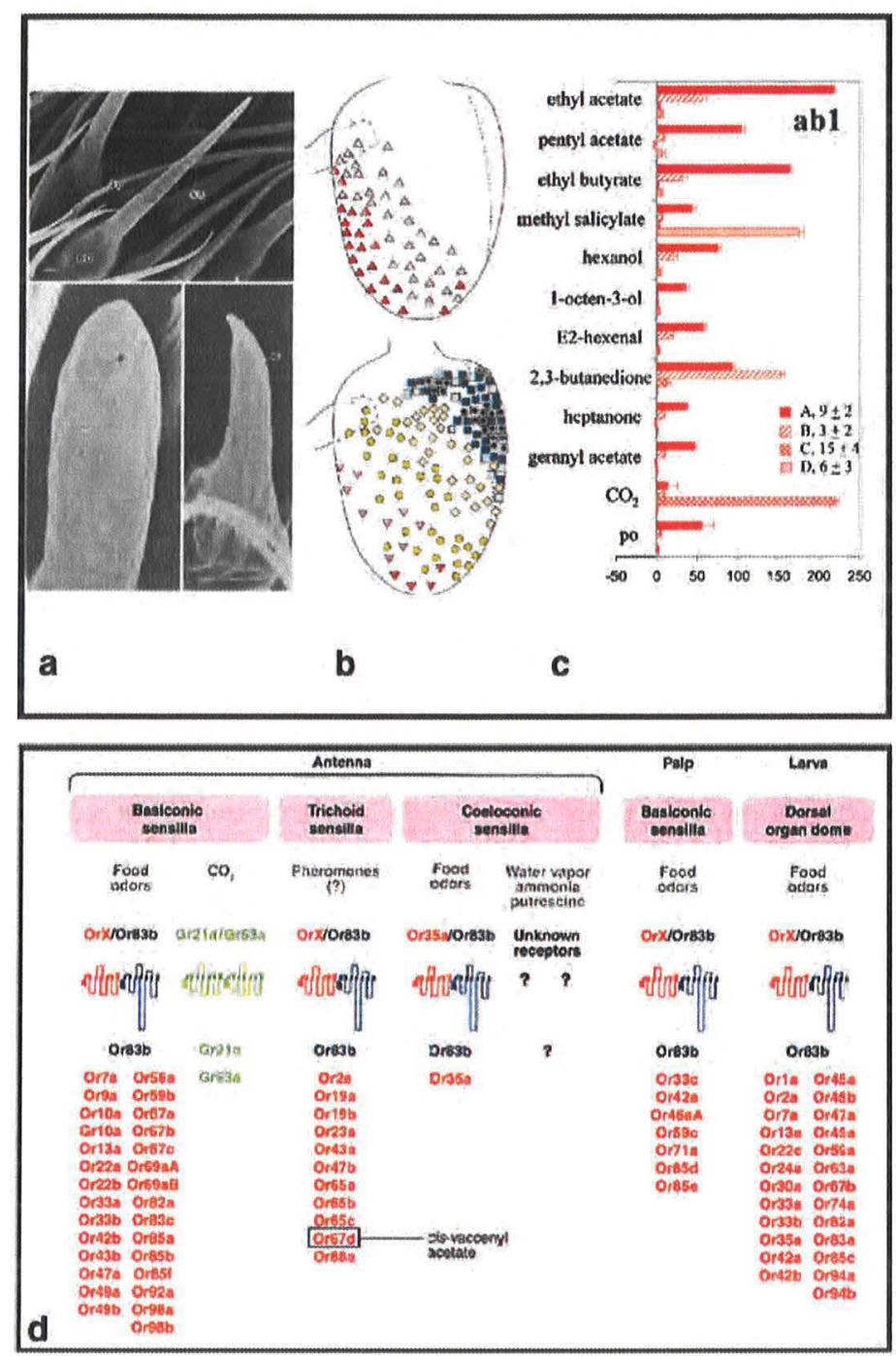

Fig. 2 Major features of the Drosophila olfactory system. a Scanning electron micrographs of trichoid, basiconic and coeloconic antennal sensilla. b Distribution of trichoid (upper panel) and basiconic (lower panel) sensilla on the anterior surface of the third antennal segment. The different symbols refer to morphological subtypes of these sensilla. The arista (stippled) is located on the lateral side of the antenna. c Response profiles of the four olfactory receptor neurons (ORNs) comprised within the basiconic sensillum type abl to a set of 11 volatile compounds and the solvent (paraffin oil, po). The data present the increase of spikes/s relative to the spontaneous firing frequency. d Inventory of Drosophila olfactory receptor proteins (ORs) expressed in the different olfactory organs of the adult and the larva, subdivided by sensillum type and possible activating odours. OR83b is an obligate coreceptor for all ORNs except the $\mathrm{CO}_{2}$-sensitive neurons expressing the gustatory receptor genes Gr2la and Gr63a. OR67d is strongly activated by the aggregation pheromone 11-cis-vaccenyl acetate. e Distribution of 31 classes of ORNs expressing 

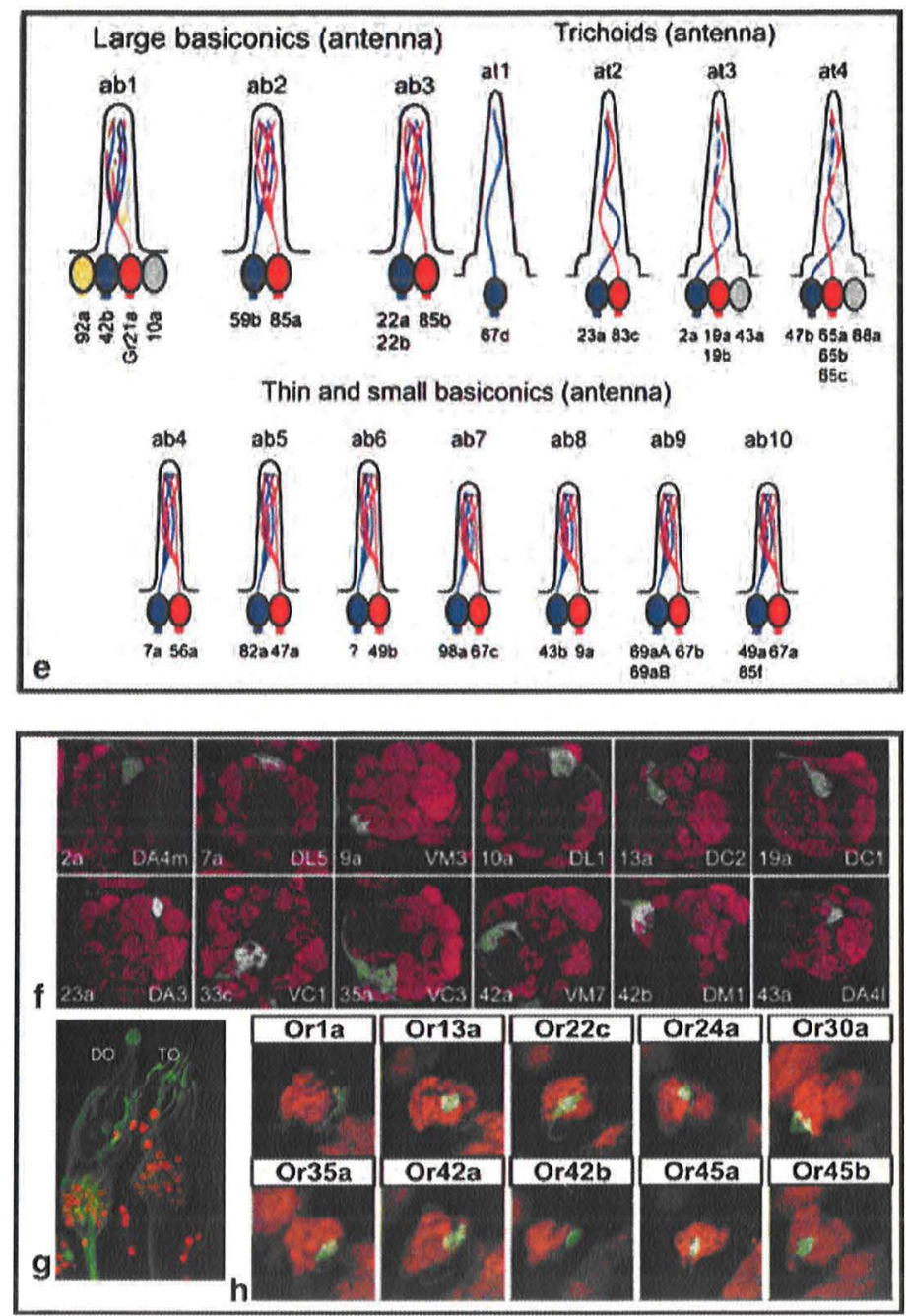

Fig. 2 (continued) specific ORs (and Gr21a) in 14 subtypes of antennal basiconic and trichoid sensilla. f Terminals of selected $O r$-green fluorescent protein (GFP) lines (green) in specific glomeruli of the adult antennal lobe, which is counterstained with the neuropile marker nc82 (magenta). The OR expressed in each type of ORN is indicated at the bottom left of each panel, the glomerular terminology is indicated on the right. Lateral is to the right. $\mathrm{g}$ Dorsal organ (DO) and terminal organ (TO) of a third instar larva labelled by the 4551-Gal4 driver line (green). Neuronal nuclei are tagged by $\alpha$-Elav staining (red). h Terminals of selected $O r$-Gal4 or $O r$-GFP lines (green) in specific glomeruli of the larval antennal lobe, counterstained with the neuropile marker nc82 (magenta). Lateral is to the left. (a, b From Shanbhag et al. (1999), copyright Elsevier. c From de Bruyne et al. (2001), copyright Elsevier. d From Vosshall and Stocker (2007), copyright Annual Reviews. e f From Couto et al. (2005), copyright Elsevier. g From Grillenzoni et al. (2007), copyright Springer. h From Fishilevich et al. (2005), copyright Elsevier) 
(de Bruyne et al. 2001; Goldman et al. 2005; Hallem and Carlson 2006; van der Goes van Naters and Carlson 2007). While basiconic sensilla are activated by food odours (de Bruyne et al. 1999, 2001), trichoid sensilla respond mainly to fly odours (van der Goes van Naters and Carlson 2007). Coeloconic sensilla comprise ORNs, as well as neurons that respond to humidity changes (Yao et al. 2005). About 50 additional, ill-characterized sensilla are found in the sacculus, a pit on the posterior side of the antenna.

The afferent fibres of the 1,100-1,250 sensory neurons from the third antennal segment (Stocker 2001) each project into single glomeruli of the antennal lobe (Stocker et al. 1983) (Figs. 1, 2). Most of the projections are bilateral, extending into corresponding glomeruli in both ipsilateral and contralateral lobes. However, about 200 fibres that terminate in five specific glomeruli (see later) remain strictly ipsilateral (Stocker et al. 1983). The antennal lobe also is the target of the 120 maxillary ORNs; their projections are bilateral throughout.

\subsection{Larval Olfactory Organs}

Adults and larvae of insects that undergo full metamorphosis display very different ways of life. Adult flies roam over considerable distance to locate nutrients or mates, while larvae, which live on the food, stay within rather limited territories. Does this entail corresponding differences in complexity of the olfactory circuitry? (For a comprehensive summary of the earlier literature, also on non-Drosophila species, see Cobb 1999.) Indeed, both olfactory organs and the central olfactory pathway are much simpler in larvae than in adults, at least in terms of cell number. The tiny larval antenna, the 'dorsal organ', and specifically its prominent 'dome' sensillum, is innervated by only 21 ORNs (Heimbeck et al. 1999; Kreher et al. 2005) (Figs. 1, 2). Larvae in which these neurons were selectively silenced by transgenic toxin expression did not respond behaviourally to odours anymore, suggesting that these neurons are the exclusive larval ORNs (Fishilevich et al. 2005; Larsson et al. 2004). They are arranged in seven triplets, corresponding to a developmental fusion of seven three-neuron-type sensilla (Grillenzoni et al. 2007). Six other sensilla that surround the dome are thought to be gustatory, rendering the dorsal organ a mixed organ for smell and taste, a situation which is not paralleled in adults.

Both the dramatic reduction of ORNs from almost 1,300 in the adult to a mere 21 in the larva and the mixed modality of the dorsal organ suggest that long-range chemosensory signals and the distinction between olfactory and gustatory cues may be less important for a substrate feeder than for a flying insect. As another discrepancy from the adult, all larval ORN projections remain exclusively ipsilateral in the brain. Interestingly, although larvae with a single functional ORN still are attracted by odorants, the accuracy of navigation is enhanced when the larva can use two identical ORNs, one on each side and both expressing the same OR (see later) (Louis et al. 2007); whether a similar improvement would be seen if two different 
kinds of ORN are functional on the same body side, however, remains to be tested. Common to both adult and larval stages is that the central targets for smell and taste are well separated: Olfactory afferents project into a glomerulus-type antennal lobe (Python and Stocker 2002; Stocker et al. 1983), whereas taste information bypasses the brain proper and rather is sent to various target regions in the suboesophageal ganglion (Colomb et al. 2007; see later) (Fig. 1).

\subsection{Odorant Receptors}

Homology-based screens for fly genes resembling vertebrate Or genes had failed for many years. Drosophila ORs were ultimately detected by searching for a family of seven-transmembrane-domain proteins that are selectively expressed in ORNs (Clyne et al. 1999; Gao and Chess 1999; Vosshall et al. 1999). The Drosophila Or gene family thus identified comprises 60 genes which encode 62 ORs (Robertson et al. 2003) (Fig. 2). Although fly ORs are characterized by seven-transmembrane domains like their mammalian counterparts (Buck and Axel 1991), the two families are not homologous. Indeed, the membrane topology of fly ORs appears to be inverted relative to that of other ORs (Benton et al. 2006), a feature whose functional implications will have to be elucidated (Sato et al. 2008; Wicher et al. 2008).

Fly ORs fall into two distinct classes: conventional, ligand-specifying ORs and the atypical OR83b, which is expressed in the large majority of adult ORNs and all 21 larval ORNs (Benton et al. 2006; Larsson et al. 2004; Vosshall et al. 1999) (Fig. 2). OR83b is an obligatory coreceptor that associates with the conventional ORs; the OR/OR83b complex is then targeted to the dendrite (Benton et al. 2006). By contrast, the conventional, ligand-specifying ORs are expressed each in a specific subpopulation of ORNs in the antenna or palp and/or the larval dorsal organ (Clyne et al. 1999; Couto et al. 2005; Fishilevich et al. 2005; Gao and Chess 1999; Goldman et al. 2005; Kreher et al. 2005, 2008; Vosshall et al. 1999). As shown by RNA in situ hybridization, 48 of these ORs are detected in adults and 25 in the larvae (Fig. 2). Twelve ORs are expressed in both larva and adult, while the rest are specific for their stage (Fishilevich et al. 2005). Why a given ORs is expressed at a given stage or in a particular olfactory organ or sensillum type is not understood. In general, each ORN expresses only one ligand-specifying OR, but there are at least seven documented cases of OR coexpression (Couto et al. 2005; Fishilevich and Vosshall 2005; Goldman et al. 2005) (Fig. 2).

Imaging of ORNs expressing a given OR or recording from 'empty' adult ORNs in which single ORs were misexpressed allows the range of ligands that can act via each OR to be identified and ORs to be assigned to a specific class of ORN and sensillum type (Dobritsa et al. 2003; Goldman et al. 2005; Hallem and Carlson 2006; Hallem et al. 2004; Kreher et al. 2005, 2008; Pelz et al. 2006) (Fig. 2). Thus, ORs expressed in antennal and palp basiconic ORNs tend to be strongly activated by general food odours (Goldman et al. 2005; Hallem and Carlson, 2006) (Fig. 2). Larval ORs are tuned either to aromatic or aliphatic food components (Kreher et al. 
2005, 2008). Distinct from these receptors, four ORs expressed in two subtypes of trichoid sensilla respond to pheromonal components, such as the aggregation pheromone 11-cis-vaccenyl acetate (Ha and Smith 2006; Kurtovic et al. 2007; van der Goes van Naters and Carlson 2007). Recently, a CD36-related receptor has been identified as a putative cofactor of ORs for pheromone detection (Benton et al. 2007). ORNs in coeloconic sensilla are mainly tuned to amines, ammonia and putrescine (Yao et al. 2005), but the identity of most of their ORs remains to be discovered. A very distinct receptor arrangement is found in a subset of antennal basiconic ORNs that are specialized for the detection of $\mathrm{CO}_{2}$. Notably, detection of this particular substance requires neither OR83b nor any of the conventional ORs, but the coexpression of the gustatory receptor genes Gr21a and Gr63a (Benton et al. 2006; Jones et al. 2007; Kwon et al. 2007; Suh et al. 2004) (Fig. 2).

\subsection{Target Glomeruli of Odorant Receptors}

The groundbreaking discovery in mice that ORNs expressing the same OR converge upon discrete glomeruli in the olfactory bulb (Mombaerts et al. 1996; Ressler et al. 1994; Vassar et al. 1994) prompted researchers to ask whether the fly uses the same logic of connectivity. Given that the adult olfactory system does its job with about 50 ORs and about 50 antennal lobe glomeruli (Couto et al. 2005; Laissue et al. 1999), Drosophila is a particularly suitable model for studying the principles of ORN wiring at the cellular level. Indeed, fly ORNs expressing a given OR were shown to target one glomerulus or exceptionally two glomeruli (Gao et al. 2000; Vosshall et al. 2000), which allowed the establishment of an almost complete OR-to-glomerulus map (Couto et al. 2005; Fishilevich and Vosshall 2005) (Fig. 2). This map comprises 46 different ORs; it assigns glomerular identity to every antennal basiconic and trichoid ORN, every palp ORN and provides indirect evidence on eight glomeruli that are targeted by ORNs from coeloconic sensilla. Six particular glomeruli deserve special attention. Three lateral, large glomeruli may be implicated in mating behaviour, because they are innervated by neurons that express fruitless, a gene which is involved in shaping the circuitry of male courtship (Manoli et al. 2005; Stockinger et al. 2005). Two of these glomeruli are good candidates for processing pheromonal cues, as they are targets of trichoid sensilla (see earlier) and are larger in males than in females (Kondoh et al. 2003; Stockinger et al. 2005). Furthermore, the most ventral glomerulus in the antennal lobe comprises the terminals of the $\mathrm{CO}_{2}$-sensitive ORNs which coexpress Gr2la and Gr63a (see earlier). Interestingly, prolonged exposure to $\mathrm{CO}_{2}$ induces a reversible volume increase in this glomerulus (Sachse et al. 2007). Finally, as shown by previous studies, two other glomeruli are the targets of six putative thermosensory or hygrosensory neurons in the featherlike antennal 'arista' (Foelix et al. 1989; Lienhard and Stocker 1987). In the present map, the identity of the innervating sensory neurons remains unknown for two glomeruli only. Interestingly, one of the target glomeruli of coeloconic ORNs (Vosshall and Stocker 2007), as well as the target glomerulus of the $\mathrm{CO}_{2}$-sensitive neurons and the two 
aristal target glomeruli receive innervation exclusively from the ipsilateral antenna; almost all other glomeruli are bilaterally innervated (Stocker 1994).

A number of conclusions can be drawn from this sensory map (Couto et al. 2005; Fishilevich and Vosshall 2005; Hallem and Carlson 2006; Stocker 1994):

1. The afferents from the antenna and the palp segregate into different glomeruli, suggesting an ability to distinguish between the two types of signals.

2. The majority of glomeruli receive bilateral inputs; however, a group of five ventral glomeruli are exclusive targets of the ipsilateral antenna.

3. Most of the glomeruli appear to be responsive to a variety of odorants, i.e. those recognized by their proper OR. These types of glomeruli are very likely involved in the processing of food odours.

4. Other glomeruli may accomplish more specialized functions, as suggested by the putative pheromone glomeruli, the $\mathrm{CO}_{2}$ glomerulus and the two aristal glomeruli.

5. Target glomeruli of basiconic, trichoid and coeloconic sensilla tend to cluster in different areas of the antennal lobe.

6. At least seven glomeruli are targeted by two types of OR, owing to coexpression in the corresponding ORNs. One particular OR is coexpressed with either of two different ORs in two types or ORNs; accordingly it has two target glomeruli.

7. A possible chemotopic arrangement of glomeruli, i.e. a clustering of glomeruli that are activated by similar odours, remains controversial (Couto et al. 2005; Fishilevich and Vosshall 2005; Hallem and Carlson 2006).

The functional significance of many of these observations will have to be shown.

\subsection{Central Olfactory Pathway in Adult Flies}

The odour information that each glomerulus receives from its corresponding ORNs is significantly processed in the antennal lobe, regarding both quantitative and qualitative parameters, such as detection threshold and odour discrimination, respectively.

The two major target neurons of the ORNs are local interneurons, which interconnect many or even all glomeruli, and projection neurons, which mostly link single glomeruli with higher olfactory centres, the mushroom bodies and the lateral horn (Stocker 1994) (Figs. 1, 4). Many of the local interneurons are GABAergic (Wilson and Laurent 2005). They receive excitatory input from ORNs and - via recurrent synapses - from projection neurons and establish inhibitory synapses with both ORNs and projection neurons. A possible role of this inhibitory network may be to synchronize projection neuron activity, within a given glomerulus and/or between projection neurons innervating different glomeruli ( $\mathrm{Ng}$ et al. 2002). Recently, a second class of cholinergic, excitatory local interneurons was identified (Olsen et al. 2007; Shang et al. 2007). These neurons likely provide the substrate for another long-known property of projection neurons, their significantly broadened odour 

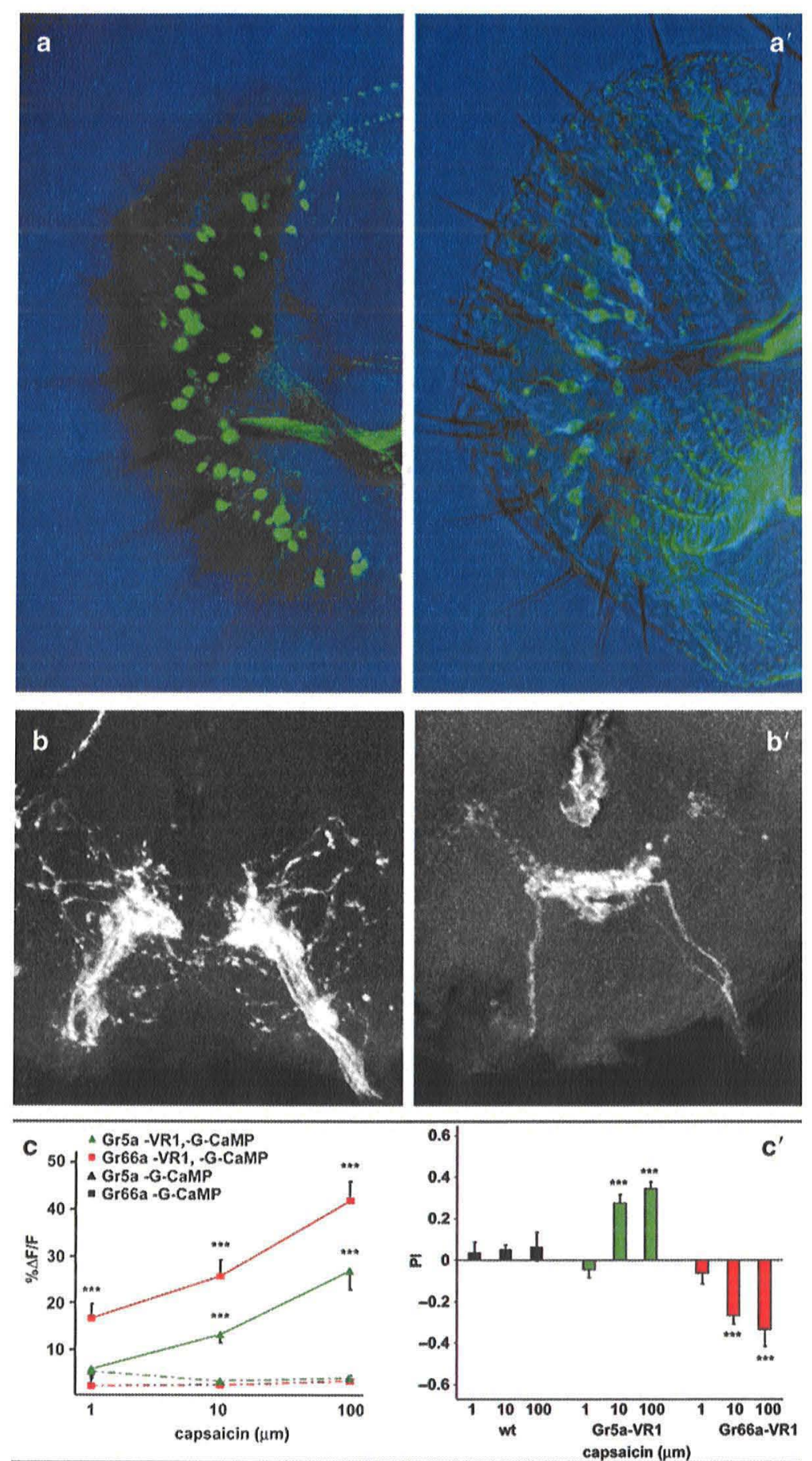
tuning compared with ORNs (Ng et al. 2002; Wilson et al. 2004). Although projection neurons get their major input from ORNs that project to their "own" glomerulus (Root et al. 2007), excitatory local interneurons allow projection neurons to respond to signals from ORNs that target neighbouring glomeruli.

The 'odour image' (Laurent 1996) represented by patterned temporal and combinatorial activity of an estimated 150 projection neurons (Stocker et al. 1997) is then transferred onto third-order neurons in the mushroom bodies and the lateral horn (Figs. 1, 4). These two higher centres are thought to control distinct olfactory functions. The mushroom bodies represent key regions for olfactory learning (see later), whereas the lateral horn appears to be involved in innate odour recognition (de Belle and Heisenberg 1994; Heimbeck et al. 2001; Jefferis et al. 2007; Tanaka et al. 2004). Uniglomerular projection neurons establish terminals in both of these centres. Their output synapses onto the about 2,500 intrinsic mushroom body neurons (the Kenyon cells) are located in the so-called calyx (Crittenden et al. 1998; Ito et al. 1997; Lee et al. 1999; Strausfeld et al. 2003; Yasuyama et al. 2002) (Fig. 1). Projection neurons deriving from specific glomeruli were shown to establish synaptic boutons preferentially in moderately specific, relatively broad zones of the calyx (Jefferis et al. 2007; Lin et al. 2007; Tanaka et al. 2004). Consistent with this observation, odour stimulation evokes spatially distinct, stereotyped activity in the calyx (Fiala et al. 2002; Wang et al. 2004a). Calycal zones were reported to correspond to the clonally and developmentally segregated dendritic arborizations of five Kenyon cell subtypes (Lin et al. 2007). Comparing the projection neuron-to-Kenyon cell map with electrophysiological data from ORNs (Hallem and Carlson 2006; Wilson et al. 2004) reportedly suggests that Kenyon cell responses in the different zones may be correlated with chemical classes of odour (Lin et al. 2007) (see, however, Murthy et al. 2008).

A prominent feature of calycal connectivity is that projection neurons synapse onto multiple Kenyon cells, and that Kenyon cells receive input from multiple projection neurons, generating an intricate local divergence-convergence network. Accordingly, Kenyon cells may act as coincidence detectors, which integrate the

Fig. 3 Two receptor genes, Gr5a and Gr66a, are expressed in different subsets of gustatory receptor neurons of the labellar chemosensilla; their axons project to separate regions in the suboesophageal ganglion; their activation induces attractive or aversive behaviour, respectively. (a) Gr5a expression at the labellum as approximated by GFP expression from the promoter-Gal4 line Gr5a-Gal4. GFP-expressing neurons are observed in all taste sensilla. While s-type sensilla have only one GFP-positive neuron, half of the 1-type sensilla have more than one GFP-positive neuron. (a') GFP expression from the Gr66a-Gal4 strain. One GFP-positive neuron is observed per s- and 1-type sensillum. (b) Projection patterns of Gr5a-Gal4-positive and of Gr66a-Gal4-positive neurons (b') in the suboesophageal ganglion. (c) When a capsaicin receptor (VR1) is transgenically expressed in either the $\mathrm{Gr} 5 a$-Gal4 or the Gr66a-Gal4 pattern, application of capsaicin can drive the respective neurons; without the transgene, no such activation is found. (c') If animals expressing VR1 in the $\mathrm{Gr} 5 \mathrm{a}$-Gal4 expression pattern are presented with capsaicin, flies prefer capsaicin, whereas if VRI is expressed in the Gr66a-Gal4 expression pattern, flies avoid capsaicin; control genotypes are behaviourally indifferent towards capsaicin. (a, a', b, b' copyright $T$. Inoshita and T. Tanimura, Kyushu University. c, c' from Marella et al. 2006, copyright Elsevier) 

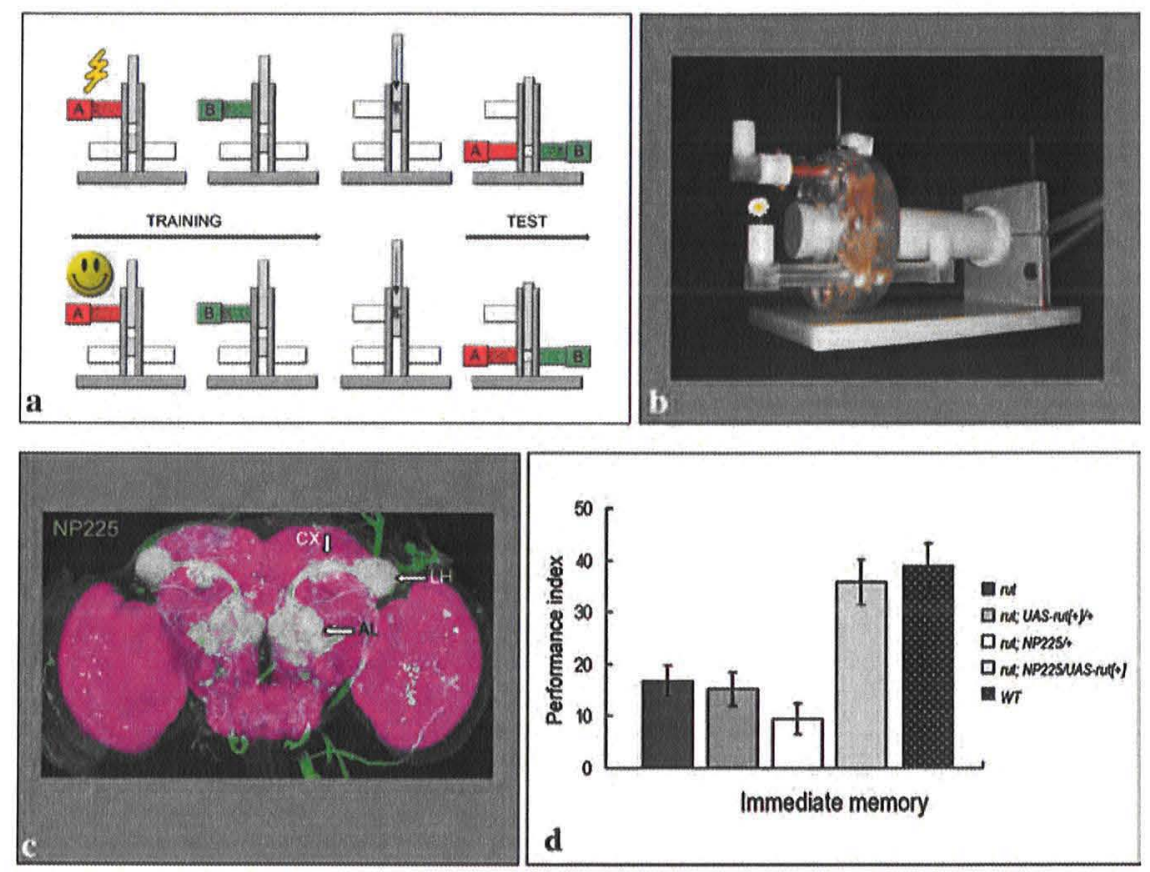

Fig. 4 Olfactory learning in adult Drosophila. a Learning experiments in adult Drosophila use a T-maze. Either electric shock as punishment (upper part) or sugar as reward (lower part) can be used as a reinforcer. In either version, about 100 flies are put in a training tube (red) where one odour (A) is paired with reinforcement. Then, a second odour (B) is applied alone (green) (a second group of flies is trained reciprocally, i.e. odour A is presented without reinforcement and odour B is presented with reinforcement). Finally, the flies are forced into an elevator and moved to a choice point where both odours are presented. Counting the number of flies on either side and comparing the distribution between reciprocally trained groups allows the learning index to be calculated. b The 'revolver' device for measuring learning with high throughput; the apparatus is partially disassembled to highlight the training tube (top) and the two testing tubes (bottom). c Expression pattern of the Gal4 line NP225 visualized by driving UAS-mCD8::GFP (green); anti-Synapsin staining as a neuropile marker (magenta). About 75 projection neurons innervating 35 glomeruli in the antennal lobe (AL) and projecting to both the mushroom body calyx $(\mathrm{CX})$ and the lateral horn (LH) are labelled. $\mathbf{d} r u t^{2080}$ mutants are impaired in appetitive olfactory learning. Both control genotypes (both in the mutant genetic background: rut ${ }^{2080}$; UAS-rut and rut ${ }^{2080}$; NP225 Gal4) also show the memory impairment. If in the mutant genetic background the rutabaga cDNA is expressed in the NP225-Gal4 pattern, learning scores are restored to wild-type (WT) level. (a, c Copyright A.S. Thum, University of Fribourg. b Copyright A. Yarali, Universität Würzburg. d Modified from Thum et al. 2007, copyright Society for Neuroscience)

odour information carried by parallel channels of projection neurons (Heisenberg 2003; Perez-Orive et al. 2002; Wang et al. 2004a). The activity patterns across the Kenyon cells are then read out by relatively few classes of mushroom body output neurons (Ito et al. 1998; Tanaka et al. 2008), which ultimately activate specific motor channels. Yet, exactly how this odour-to-behaviour switchboard at the mushroom body output is organized remains a mystery. 
Regarding the connectivity in the lateral horn, the most striking feature observed is a segregation of terminals between putative pheromone-representing projection neurons - which get their inputs from the two putative pheromone glomeruli (see earlier) - and 'normal' projection neurons (Jefferis et al. 2007; Schlief and Wilson 2007). Interestingly, the candidate pheromone region in the lateral horn receives both excitatory and inhibitory signals from the two glomeruli, the former via cholinergic projection neurons and the latter via GABA-positive projection neurons (Jefferis et al. 2007). Balanced excitation and inhibition of these pathways may allow lateral horn neurons to mediate behavioural alternatives, depending on the attractive or repulsive nature of the pheromone. Not unexpectedly, sexually dimorphic connectivity has been observed in the pheromone region (Datta et al. 2008). Normal projection neurons, which are mostly activated by food odours, establish stereotypic, largely overlapping patterns of terminals (Jefferis et al. 2007; Marin et al. 2002; Wong et al. 2002). Thus, information about food appears to become intensely integrated across antennal input channels within the mushroom body and the lateral horn, whereas pheromones may be signalled via discrete channels all the way from the sensory periphery to the lateral horn. This may correspond to the evolutionarily fixed and discrete behavioural 'meaning' of different pheromones, as contrasted with a requirement for an integrated sensory-motor switchboard for general odours.

A number of putative third-order neurons have been identified in the lateral horn (Jefferis et al. 2007; Tanaka et al. 2004); however, their roles in mediating odourdriven behaviours are hard to predict, because their dendritic fields overlap with many classes of projection neurons and because they target different brain areas. Establishing a complete neuronal circuit diagram of such behavioural programmes will require the identification of the as yet unknown downstream premotor and motor neurons as well as of biologically meaningful behavioural 'modules'.

\subsection{Larval Olfactory Pathway}

The larval central olfactory pathway largely shares the layout and the types of neurons of its adult counterpart, but is much simpler in terms of cell numbers (Python and Stocker 2002). Similar to the situation in adults, the 21 larval ORNs target single glomeruli in the antennal lobe (Figs. 1,2). However, larval glomeruli do not represent sites of ORN convergence. Rather, every ORN (each expressing its proper OR) has its own glomerulus among a total of 21 glomeruli (Fishilevich et al. 2005; Kreher et al. 2005; Ramaekers et al. 2005) (Figs. 1,2). Recently, Kreher et al. (2008) reported that the similarity in ORN activation pattern allows a partial prediction of behavioural odour similarity, based on masking experiments. In any event, as in the adult, local interneurons establish horizontal connections between glomeruli (Ramaekers et al. 2005) and most of the larval projection neurons are of the uniglomerular type (Marin et al. 2005; Ramaekers et al. 2005). Each glomerulus appears to be innervated only by one or a few projection neurons (Ramaekers et al. 2005), suggesting that their total number may not be much higher than the number of glomeruli. 
Similar to the situation in the adult, projection neurons target both the mushroom bodies and the lateral horn (Fig. 1). The lateral horn circuitry has not been addressed so far. Studying the output connectivity of larval projection neurons in the mushroom body was simplified by the fact that the larval calyx comprises about 30-40 relatively large, identifiable structures, called 'calyx glomeruli' (Marin et al. 2005; Masuda-Nakagawa et al. 2005; Ramaekers et al. 2005). Projection neurons choose mostly single, exceptionally two calyx glomeruli as targets (Marin et al. 2005; Ramaekers et al. 2005). Each of them is innervated by only one or a few projection neurons. Many of these neurons were shown to each stereotypically connect a specific antennal lobe glomerulus with a specific calyx glomerulus (Ramaekers et al. 2005).

While some of the larval Kenyon cells innervate a single calyx glomerulus (Ramaekers et al. 2005), many establish dendritic arbours in usually six, apparently randomly selected glomeruli (Masuda-Nakagawa et al. 2005; Murthy et al. 2008). Thus, as in adults, projection neurons diverge onto multiple Kenyon cells, and most Kenyon cells receive input from multiple projection neurons, again providing a local divergence-convergence connectivity (Masuda-Nakagawa et al. 2005; Murthy et al. 2008). Finally, it should be noted that the two types of Kenyon cells, i.e. the ones receiving input in one or multiple calyx glomeruli, may allow different modes of signal transfer, acting either in elementary odour coding or as coincidence detectors for interpreting combined activity (Heisenberg 2003; Perez-Orive et al. 2002).

In conclusion, the general organization of the central olfactory pathway in the larva is similar to that in the adult (Fig. 1) and still shares the essential layout of the vertebrate olfactory system. Yet, the larval circuit displays a number of specific properties. Firstly, every larval ORN and probably most of the larval projection neurons are unique (Ramaekers et al. 2005). Any loss of these cells should theoretically affect olfactory function more severely than in the adult system. However, silencing of single or even multiple ORNs had surprisingly little effect on larval odour-driven behaviour, implying that the ligand receptive ranges of the different ORs must be largely overlapping (Fishilevich et al. 2005). Secondly, the presence of only 21 antennal lobe glomeruli suggests that the number of primary olfactory dimensions is reduced in the larva compared with adult flies comprising about 50 glomeruli. Thirdly, given that the numbers of ORNs, antennal lobe glomeruli, projection neurons and calyx glomeruli are almost the same, the larval olfactory pathway lacks convergent and divergent connectivity up to the mushroom bodies (Ramaekers et al. 2005) (Fig. 1). This contrasts with the adult olfactory circuit, in which 1,300 ORNs converge onto 50 glomeruli, which diverge again to an estimated 150 projection neurons, each of which innervates a broad zone of the calyx. The lack of cellular redundancy, the reduced number of primary olfactory dimensions and the lack of convergent connectivity in the antennal lobe are likely to reduce the signalto-noise ratio. Hence, larvae can be expected to be relatively poorer in odour discrimination than adult flies. Yet, for the simple discrimination tasks of a substrate feeder this may not be a too serious drawback. Given its mere 21 primary olfactory dimensions, the larva is an ideally suited comprehensive model for analyzing the translation of olfactory input into behavioral output (Kreher et al. 2008; Hoare et al. 2008). 


\section{Tasting}

After having been tracked down using visual and/or olfactory cues, contact chemosensation serves to immediately handle things in physical contact with the animal. In insects it contributes to diverse behaviour functions: selection of oviposition sites in butterflies (Feeny et al. 1983); kin and/or nestmate recognition to support nepotism in ants (Ozaki et al. 2005); and the pursuit of courtship (Ferveur 2005; Lacaille et al. 2007). Most obviously, however, contact chemosensation organizes eating and drinking behaviour (the 'taste' system). Here, we chose not to mention much of the fascinating biology of contact chemosensation in insects and restrict ourselves largely to how taste function is organized in Drosophila.

To start with the most striking difference to vertebrates, gustatory receptor neurons in Drosophila, as in insects in general, are primary sensory neurons, in contrast to the situation in vertebrates where taste cells originate from the epidermis and only are innervated by neurons. Also, the gene family coding for sugar- and bitter-sensitive gustatory receptor proteins is not apparently homologous to the functionally corresponding gene family in vertebrates (Clyne et al. 2000; Robertson et al. 2003; Scott et al. 2001); this, as in the case for olfaction, argues for quite some degree of evolutionary divergence in the chemosensory systems of insects versus vertebrates. Still, if even under such conditions functional similarities are found, these may be particularly good hints towards common functional constraints on taste processing.

Indeed, there are a number of similarities. The taste system of Drosophila seems to categorize sensory inputs into relatively few modalities, including sweet, salt and bitter. Regarding sweet, this is achieved by coexpression of gustatory receptor proteins with distinct sugar-ligand profiles within the same gustatory sensory neuron; a similar architecture likely applies to bitter as well. Sour taste may be detected by a depression of the sugar response. In addition, water-sensitive neurons are included in many taste organs, which in vertebrates is not typically the case. Still, the relatively few dimensions of taste, in particular the lower dimensionality of taste compared with olfaction, and the logic of coexpression of multiple gustatory receptor genes in a given sensory neuron for either sweet or bitter taste seem to generally conform with the situation in vertebrates.

The taste sensilla of Drosophila are cuticular, hairlike structures with a single pore at the tip into which two or four gustatory receptor neurons send their dendrites (Falk et al. 1976; Ishimoto and Tanimura 2004). Taste sensilla typically include, in addition to three non-neuronal cells with homeostatic function, also one mechanosensory neuron, serving to integrate the 'what' with the 'where'. Thus, taste is most closely entangled with touch, also in development (Awasaki and Kimura 1997). Such organization is similarly found in mammals, as taste neurons are grouped into taste 'buds', as taste and touch sensory neurons are intermingled on the tongue, and as gustatory and somatosensory cortex are closely entangled functionally (Kaas 2005).

Taste sensilla can be found both on multiple external sense organs, used to probe the environment before ingestion, and at internal sense organs, used to monitor the 
quality of already ingested food (Fig. 1); such an architecture is also seen in mammals. The projections from both kinds of organ typically bypass the brain proper, and rather send their axons to the suboesophageal ganglion; here, in concert with centrifugal interneurons, ingestion behaviour is thought to be organized. This triad of contact-chemosensory input, ingestion-related motor output and central motivating factors comprises the 'taste system' of Drosophila. How does this system work?

\subsection{Adult}

Adult flies taste with their 'feet' (i.e. tarsi), with their 'tongue' (i.e. labellum), with taste neurons along their pharynx, and additionally have contact chemosensory neurons at their wing margin (Stocker 1994; Singh 1998) (Fig. 1). The external taste organs of the adult comprise hair-shaped sensilla and conically shaped pegs.

After initial contact of a tastant via the tarsi, flies initiate extension of the proboscis (such proboscis extension can also happen by direct stimulation of labellar sensilla). This brings the tastant into contact with labellar sensilla and makes the flies open the labellar lobes. This exposes a set of taste pegs buried in the ridges of the opened labellum to the tastant (Fig. 1), to finally trigger ingestion. The quality of ingested food can then be monitored with three different taste organs along the pharynx (i.e. labral, ventral cibarial and dorsal cibarial sense organ).

Inputs from labellum, pharynx and the tarsi are collected in the suboesophageal ganglion, where taste information is integrated with centrifugal interneurons to organize ingestion behaviour.

\subsubsection{Taste Neurons at Tarsi}

On the fore-, mid-, and hindlegs, contact chemosensilla are located on the tarsal segments (Fig. 1). On the forelegs, the numbers of such electrophysiologically confirmed sensilla differ between sexes (females have 18 sensilla, males have 28) (Meunier et al. 2000; Meunier et al. 2003), likely related to males using their forelegs to touch the female abdomen just before copulation. On the basis of their electrophysiological profiles, the tarsal sensilla are classified into A- B- and C-type sensilla (see later).

Different from the situation on the labellum (see later), not all tarsal sensilla contain a sugar-sensitive sensory neuron (Meunier et al. 2000). Also, the response spectra of the tarsal sensory neurons differ from those of labellar sensilla. That is, labellar contact chemosensory neurons are classically called S, W, L1 or L2 neurons (Ishimoto and Tanimura. 2004), on the basis of their electrophysiological response spectra. The $\mathrm{L}$ neurons are activated by salt, in the case of $\mathrm{L} 1$ with a low threshold (typically no electrophysiological responses are seen for concentrations below $10 \mathrm{mM}$; Fujishiro et al. 1984) and in the case of L2 neurons with a high threshold; L2 neurons can in some cases also be activated by bitter compounds. 
W cells are activated by pure water, a response which typically can be inhibited by high osmolarity, i.e. higher than a few hundred millimolar sugars and salts. S cells are activated by sugars and can be inhibited by bitter substances. Are these kinds of cells also found on the tarsi?

For the tarsal A-type sensilla (Meunier et al. 2000), spikes from S, W and L1 cells can be discerned, and the water response can inhibited by high osmolarity. In B-type sensilla, responses to sugars are observed only phasically, during 100-200 ms after stimulation, while otherwise such responses are more sustained. Also, in the B-type sensilla, the W cell is not inhibited by high osomolarity. In C-type sensilla, only a W cell has so far been identified electrophysiologically, which however is not inhibited by high osmolarity. As the neurons in a number of tarsal sensilla do not respond to any compound examined so far, they cannot be classified yet as A-, B- or C-type. Furthermore, there also are bitter-sensitive neurons on the tarsi, as the proboscis extension reflex to sugars can be suppressed by bitter compounds applied to the tarsi. Indeed, electrophysiological studies revealed that in specific tarsal sensilla there are L2 neurons which do respond to bitter compounds (Meunier et al. 2003). Interestingly, the initiation of spikes in these bitter-sensitive neurons has a delay of up to $200 \mathrm{~ms}$; this delay is shortened as the concentration of the bitter substance increases. Strikingly, the same long delay is seen for the inhibitory effect of bitter substances on the S and W cells, even in sensilla that do not contain an L2 neuron. Similarly long delays likely are typical for electrophysiological bitter responses in labellar sensilla as well. One explanation for these long latencies may be that bitter compounds need to diffuse into the receptor cells to activate receptor sites; given that many bitter substances are hydrophobic, such a process may take some time. To summarize, tarsal chemosensilla are special in quite some respects.

\subsubsection{Taste Neurons at Labellar Taste Pegs}

The labellum of Drosophila is decorated on its bottom surface with numerous ridges called pseudotrachea (Shanbhag et al. 2001). Along these pseudotrachea, multiple rows of a total of about 30-40 taste pegs are located (Fig. 1). When flies are sucking liquid food, the fluid passes this pseudotracheal ridge system, which eventually merges to the actual mouth opening. Thus, the taste pegs are guideposts for ingestion, triggering pumping behaviour. Taste pegs are distinct from regular taste sensilla in that each taste peg is innervated by only one gustatory sensory neuron together with one mechanosensory neuron. The number of taste pegs is variable among individuals and differs between sexes. Interestingly, in poxn mutants (CG8246, poxn ${ }^{70-23}$; Awasaki and Kimura 1997) only the neurons in the external taste sensilla, but not in the internal taste sensilla and labellar pegs, are transformed into mechanosensory neurons (Awasaki and Kimura 1997). In such mutants, sugar still can enhance and bitter substances can still reduce food uptake. This suggests that chemoreception via internal taste organs and/or taste pegs provides the necessary information for these kinds of behaviour effect. No electrophysiological studies have been performed on the respective taste sensory neurons, as it is difficult to 
fixate the labellum such that the taste pegs in the pseudotracheal ridges, not to mention the internal sense organs, are accessible (but see Dethier and Hanson 1964 for such recordings in the blowfly).

However, with transgenic techniques hints towards the function of the taste pegs could be obtained. With use of the enhancer trap line E409, which supports transgene expression in the taste pegs (and in the mushroom bodies), a novel functional class of gustatory sensory neurons, distinct from $\mathrm{Gr} 5 \mathrm{a}$-Gal4- and $\mathrm{Gr} 66 \mathrm{a}$-Gal4-positive neurons (see later) was identified (Fischler et al. 2007). With use of $\mathrm{Ca}^{2+}$ imaging at the target region of these neurons in the suboesophageal ganglion, it was found that they can be activated by carbonated water. Behaviourally, stimulation with carbonated water elicits feeding. Silencing the E409-positive neurons abolishes these behavioural responses, whereas driving these cells (by means of ectopically expressing a capsaicin receptor and then stimulating with capsaicin) triggers proboscis extension (note, however, that airborne $\mathrm{CO}_{2}$ is a repellent for Drosophila; Faucher et al. 2006; Suh et al. 2004).

\subsubsection{Taste Neurons at Labellar Sensilla}

On the labellum, there are 31 contact chemosensilla, each containing two to four gustatory and one mechanosensory neuron. They are classified into three types (Shanbhag et al. 2001; Hiroi et al. 2002). The s-type sensilla are short, house four gustatory sensory neurons and are located near the opening of the labellum. The i-type sensilla are intermediate in size and contain two gustatory sensory neurons; they are located mostly on the anterior and posterior part of the labellum. The l-type sensilla are long, possess four gustatory sensory neurons and are located such that they can contact the substrate even when the labellum is closed, suggesting a role in initiating labellar opening. Each individual labellar sensillum can be identified across subjects by its specific location. The axons from all labellar gustatory sensory neurons project towards the suboesophageal ganglion.

Drosophila possesses nine 1-type sensilla. They house the W, S, L1 and L2 neurons, classified on the basis of their electrophysiological characteristics (Fujishiro et al. 1984). Activation of $\mathrm{W}, \mathrm{S}$ and $\mathrm{L} 1$ cells can trigger ingestion, while activity in $\mathrm{L} 2$ neurons inhibits it. Bitter substances, which - just as high $\mathrm{NaCl}$ concentrations - can activate L2 neurons in i- and s-type sensilla (see later), do not do so in L2 neurons of 1-type sensilla; whether and which non- $\mathrm{NaCl}$ compounds might stimulate these cells remains to be investigated. In all 1-type sensilla, sugar responses can be inhibited by bitter compounds.

Neither of the two gustatory sensory neurons in the nine to ten i-type sensilla is water-sensitive (Hiroi et al. 2004). One type of neuron responds to sugar as well as to $\mathrm{NaCl}$ with low threshold. Given that low $\mathrm{NaCl}$ concentrations are behaviourally attractive, these cells would seem to indiscriminatively report 'edible'. The other neuron type responds to $\mathrm{NaCl}$ with high threshold, as well as to bitter compounds. As both kinds of substance are potentially toxic, these cells seem to indiscriminatively report 'non-edible'. Interestingly, in the so far examined i-type sensilla on the 
proboscis this type of neuron also responsd to the pheromone (Z)-7-tricosene at subnanomolar concentration (Lacaille et al. 2007). This compound from the male cuticle, just as the bitter substances which activate these cells, inhibits male-male courtship. Furthermore, if one leg is stimulated with sugar, both kinds of compound can inhibit proboscis extension when applied to the other leg. Finally, adaptation to (Z)-7-tricosene reduces subsequent electrophysiological responses also to bitter substances, collectively suggesting that both kinds of stimulus may use the same input channel.

Finally, regarding the 12-13 s-type sensilla, electrophysiological recordings are scarce. Hiroi et al. (2002) reported responses to sucrose and other sugars from a few sensilla, but obviously the range of activating compounds for the four gustatory sensory neurons in these sensilla still needs to be examined in more detail.

\subsubsection{Taste Neurons at Pharyngeal Taste Organs}

There are five internal sense organs along the pharynx: the labral sense organ, the ventral and dorsal cibarial sense organs, the ventral sense organ and one dorsal row of 'fishtrap' bristles (Fig. 1). Whereas most of the neurons in these organs may be gustatory, the monoinnervated fishtrap bristles and many of the neurons of the labral sense organ appear to be mechanosensory (Nayak and Singh 1983). Interestingly, most of these sensory neurons have persisted from the larval period (Gendre et al. 2004), suggesting some persistence of taste function between larva and adult. In any event, for all pharyngeal sensilla, the compounds to excite these neurons and the behaviours relying on their input are unknown.

\subsubsection{Receptor Genes: Sweet and Bitter}

At present, the functional architecture of gustatory receptor gene expression, in particular for sweet and bitter, is being unravelled; however, the functional configuration of these receptors as monomer, dimers or oligomers is not clear, and neither are their downstream intracellular signalling cascades, the transmitter used by their host sensory neurons and the precise connectivity of these cells to second-order interneurons.

Recently, an about 60-member family of putative gustatory receptor genes was found (the $G r$ family; Clyne et al. 2000). Promoter-Gal4 strains are widely used to approximate their expression patterns and ligand profiles. We largely restrict our discussion to the three best understood $G r$ genes, namely Gr5a, Gr64a-f and Gr66a (Fig. 3). This ignores the richness of $G r$ processing, in particular with regard to the emerging understanding of pheromone function including the role of ligand-binding proteins in this respect (Shanbhag et al. 2001; Park et al. 2006; Matsuo et al. 2007).

Gr5a codes for the trehalose receptor identified earlier on the basis of classical genetics and electrophysiology (Tanimura et al. 1982, 1988; Dahanukar et al. 2001; Ueno et al. 2001). As seen in Fig. 3, it is expressed in all S cells of all three sensillar types on the labellum (Wang et al. 2004b). Central projections of the Gr5a-Gal4- 
positive neurons target the suboesophageal ganglion in a relatively lateral and anterior region (Wang et al. 2004b). In addition, a subset of contact chemosensilla on the legs is included in the Gr5a-Gal4 expression pattern, which send projections to their cognate thoracic ganglion (Wang et al. 2004b). Notably, ectopic expression in cultured cells combined with $\mathrm{Ca}^{2+}$ imaging reveals that this protein specifically binds to trehalose at micromolar ranges (Chyb et al. 2003). In vivo, Gr5a-Gal4positive neurons are activated by all sugars tested (arabinose, fructose, galactose, glucose, maltose, sucrose, trehalose) and reportedly also by $\mathrm{NaCl}$ with low (10 $\mathrm{mM}$ ) threshold, but not by bitter compounds (caffeine, denantonium) (Marella et al. 2006). Strikingly, in null mutants for Gr5a, phenotypes are more specific: electrophysiological responses are abolished for only four out of 14 sugars tested (trehalose, methyl- $\alpha$-glucoside, glucose, melezitose) (Dahanukar et al. 2007); this defect can be restored by expression of the Gr5a protein from a Gr5a-Gal4 driver. Preliminary data (Slone et al. 2007; Jiao et al. 2007) may suggest that Gr5a and members of the Gr64b-f gene group produce dimers for trehalose detection; indeed, Dahanukar et al. (2007) propose concordant expression of Gr64f and Gr5a.

As the Gr5a protein is dispensable for the electrophysiological responses to many sugars, but as $G r 5 a$-Gal4-positive neurons have a broader activation profile than the requirement of the Gr5a protein suggests, one wonders which other members of the $G r$ gene family, expressed in the same set of neurons, might be responsible for this discrepancy. Deleting the Gr64a gene abolishes (maltotriose, stachyose, raffinose, leucrose, fructose) or partially reduces (sucrose, maltose, turanose, maltitol, palatinose) the Gr5a-independent effects (Dahanukar et al. 2007). Rescue expression of Gr64a driven by $G r 5 a$-Gal4 notably restores these deficits. All electrophysiological responses to all the sugars tested were fully abolished in Gr5-Gr64a double mutants. Most importantly, behavioural analyses using the proboscis extension response conform with the complementary requirement of Gr5a and Gr64a for detecting different kinds of sugars; if both genes are deleted, proboscis extension responses to all sugars tested (note that this analysis did not include trehalose), but not towards very low concentration $\mathrm{NaCl}(5 \mathrm{mM})$, are fully abolished (Dahanukar et al. 2007). Consistently, if the Gr5a-Gal4-positive neurons are disabled by transgenic toxin expression (Wang et al. 2004b), proboscis extension to all sugars tested (trehalose, low [5 mM] concentration sucrose, glucose) as well as to very low $\mathrm{NaCl}$ concentrations is abolished, but the suppression of high $[100 \mathrm{mM}]$ concentration sucrose responses by added high-concentration $\mathrm{NaCl}$ or bitter compounds remains intact; this is consistent with Gr5a and Gr64a being expressed in the same set of cells.

The complementary involvement of Gr5a and Gr64a for detecting different kinds of sugar, together with their proposed concordant expression (Dahanukar et al. 2007), suggests they act as independent sensors within the same cell. Such an architecture is a good example for the functional logic of the taste system: it is as if differential behaviour to both classes of sugar were deliberately precluded.

In contrast, Gr66a-Gal4-positive neurons seem to be devoted to processing 'bad' (Moon et al. 2006). The Gr66a-Gal4 pattern covers one neuron each in the i- and s-type labellar sensilla (Fig. 3), and several sensilla on the legs; in all cases, these cells are non-overlapping with Gr5a-Gal4 (Wang et al. 2004b; Dahanukar 
et al. 2007). Different from Gr5a-Gal4, Gr66a-Gal4 also shows expression in the pharyngeal sense organs (Wang et al. 2004b). The central projections of Gr66a-Gal4-positive versus $\mathrm{Gr} 5 a$-Gal4-positive neurons also are non-overlapping, in that Gr66a-Gal4-positive neurons from the labellum project to more posterior and medial portions of the suboesophageal ganglion. Finally, projections from the legs reportedly target the suboesophageal ganglion in the case of Gr66a-Gal4, but the thoracic ganglia in the case of Gr5a-Gal4 (Wang et al. 2004b). Disabling Gr66a-Gal4-positive neurons leaves proboscis extension to all sugars tested (trehalose, sucrose, glucose) as well as to very low (5 mM) NaCl intact; in contrast, these flies cannot suppress proboscis extension to sucrose when bitter compounds (berberine, caffeine, denantonium, quinine) are added to the sucrose solution, whereas such suppression by high concentrations $(100-1,000 \mathrm{mM})$ of $\mathrm{NaCl}$ remains intact (Wang et al. 2004b). As shown by in vivo imaging, Gr66a-Gal4-positive neurons are activated by these and other bitter compounds (aristolochic acid, azadirachtin, limonin, lobeline, papaverine, quassin), but not by any of the sugars tested (Marella et al. 2006). Furthermore, flies transgenically expressing a capsaicin receptor in the $G r 66 a$-Gal4 pattern show avoidance of capsaicin, a substance to which normal flies reportedly are indifferent; in turn, such capsaicin expression in Gr5a-Gal4 neurons induces attraction (Marella et al. 2006).

Interestingly, Gr66a-Gal4-positive neurons can also be activated by $\mathrm{NaCl}$, with high threshold (above $10 \mathrm{mM}$ ) (Marella et al. 2006). This suggests additional expression of a high-threshold $\mathrm{NaCl}$ sensor in these cells. As high concentrations of $\mathrm{NaCl}$ still are behaviourally active even when these cells are disabled (Wang et al. 2004b), one such salt sensor may well be expressed outside the Gr66a-Gal4 pattern. Furthermore, it seems as if genetically defined subsets of Gr66a-Gal4-positive neurons were all activated by the same kinds of bitter ligands (Marella et al. 2006), lending at present no support for a functional heterogeneity within these neurons.

\subsubsection{Sensor Genes: $\mathrm{NaCl}$}

Processing of low and high $\mathrm{NaCl}$ concentrations is distinct: (1) low salt concentrations are attractive, but high salt concentrations suppress proboscis extension and lead to avoidance; (2) L1 cells respond best to low concentrations, whereas L2 neurons respond to high concentrations only; (3) Gr66a-Gal4 cells are activated only by high concentration. Thus, there must be two kinds of $\mathrm{NaCl}$ sensor, one with low threshold, expressed in L1 neurons, and one with high threshold, expressed in L2/Gr66a-Gal4 neurons plus possibly in some additional as yet uncharacterized non-Gr66a/non-L2 cells. Both processes likely involve discrete molecular sensor mechanisms, as one member of the pickpocket ( $p p k)$ gene family ( $p p k 11)$ is necessary for the behavioural responses to low salt, but is dispensable for the aversive responses to high salt; high $\mathrm{NaCl}$ responses may be mediated by another $p p k$ gene, $p p k 19$ (Liu et al. 2003a). The ppk gene family is homologous to the vertebrate epithelial $\mathrm{Na}^{+}$-channel/degenerin gene family $(\mathrm{ENaC})$, different members of which supposedly act as sensors for salt in vertebrates (Lindemann 2001). 


\subsubsection{Interplay: Combinatorial Coding of Taste?}

Strikingly, Marella et al. (2006) report that neurons covered by $\mathrm{Gr} 5 a$-Gal4 are activated not only by sugars, but also by both low $(10 \mathrm{mM})$ and high $(1 \mathrm{M})$ salt concentrations; correspondingly, Wang et al. (2004b) report that disabling Gr5aGal4-positive neurons abolishes behavioural responses not only to sugars but also to very low $(5 \mathrm{mM})$ concentrations of salt. As it is possible that at least in some sensilla Gr5a-Gal4 labels more than one neuron (Inoshita and Tanimura, unpublished results), these data speak to the set of $\mathrm{Gr} 5 \mathrm{a}$-Gal4-positive neurons as a whole; that is, it remains unclear whether indeed one and the same cell can be activated by sugars and low and high salt concentrations. Actually, electrophysiological sensilla recordings do not support this notion. Still, if this were so (as is the case in i-type sensilla which house neurons activated by both high salt and bitter, and neurons which are activated by sugars and low salt; Hiroi et al. 2004), a discrimination between these three kinds of tastant would need to rely on combinatorial coding downstream of the gustatory sensory neurons. Obviously, looking at the connectivity towards and the physiological function of gustatory interneurons now is highly warranted. Such studies are still in their infancy, and the few ones available (e.g. Bader et al. 2007; Hammer 1993; Melcher and Pankratz 2005) have so far not addressed the issue of gustatory coding, but rather have focused on the 'valuation' of tastants.

Still, in a completely different sense, combinatorial activity patterns obviously are used by flies, e.g. when combining chemosensory information from various legs to locate a food source, or when monitoring the stage of ingestion by combining taste information from the sense organs located at the various stages of ingestion.

\subsubsection{Watery}

At present, nothing is known about the molecular mechanism of water sensation. However, the NP1017-Gal4 strain covers sensory neurons likely responsible for watery taste (Inoshita and Tanimura 2006). This strain marks one sensory neuron per taste sensillum in s- and 1-type sensilla on the labellum; it expresses Gal4 in taste pegs of the labellar pseudotrachea, as well as in taste sensilla on the tarsi, and in contact chemosensory neurons on the wing margin. If these neurons are disabled, proboscis extension towards water stimulation is severely reduced, but responses to glucose as well as the suppression of proboscis extension by adding high-concentration $\mathrm{NaCl}$ to the sugar stimulus remain intact. Ablating these cells abolishes the electrophysiological responses of labellar l-type sensilla to water, but leaves sugar and salt responses in these sensilla intact. The projections of NP1017-Gal4-positive neurons from the labellum target the suboesophageal ganglion; however, the projections from the labellar sensilla and the pegs of the labellar pseudotracheae have distinct target sites in the central versus the lateral anterior region. The projection from labellar NP1017-Gal4-positive neurons overlaps with that from Gr5a-Gal4-positive cells, indicating that inputs from water- and sugar-sensing cells may to some extent be funnelled into a common pathway. 


\subsection{Larva}

Larval behaviour towards tastants is very similar to what is observed in adults. Larvae show preference for sugars, avoidance of various bitter substances and dose-dependent responses to salt: at low concentrations, larvae are attracted and at high concentrations they are repelled by $\mathrm{NaCl}$, the concentration of draw being 0.2 M (Miyakawa 1982; Liu et al. 2003a; Niewalda et al. 2008). Interestingly, Miyakawa (1982) reported preference for low-concentration $(0.01 \mathrm{M}) \mathrm{NaCl}$ remaining intact even in situations where glucose is presented at saturated concentration, suggesting at least some functional independence between glucose and low-salt processing. In contrast, low concentrations of sucrose or fructose reportedly could not be detected by the larvae in the presence of high-concentration glucose (compare Dahanukar et al. 2008).

The chemosensory equipment of the larval head comprises three external sense organs - dorsal, terminal and ventral organs-and three pharyngeal organs (Gendre et al. 2004; Python and Stocker 2002; Singh and Singh 1984) (Fig. 1). Each organ includes several multineuronal sensilla. The dorsal organ is composed of the olfactory dome sensillum (see earlier) and six smaller sensilla. Five of them and most of the terminal, ventral and pharyngeal sensilla are characterized by a distal pore, suggesting gustatory function (for Musca, see Chu and Axtell 1971; Chu-Wang and Axtell 1972). However, thermosensory (Liu et al. 2003b), hygrosensory or mechanosensory neurons may also be present. The estimated 90 per body side taste neurons of the larva (Colomb et al. 2007) outnumber the 21 ORNs (see earlier), consistent with an expected predominant short-range chemical orientation and proverbial (Carle 1969) feeding obsession of the larva. By contrast, in the flying adults, about 1,300 ORNs (Stocker 2001) outnumber approximately 600 taste neurons (Stocker 1994).

The patterns of expression of $G r$ genes in larval sensilla-studied using promoter-Gal4 strains-are only partially described (Colomb et al. 2007; Fishilevich et al. 2005; Scott et al. 2001). Notably, none of the Gr5a-Gal4 strains available show any expression in the larva (Colomb et al. 2007). Gr2a, Gr21a, Gr22e, Gr28be, Gr32a and $G r 66 a$, known to be expressed in the adult, are also expressed in the larva, that is in the terminal organ. Gr2a-Gal4 labels in addition two neurons in the dorsal organ. In adults, Gr22e, Gr28be, Gr32a and Gr66a are suspected to encode bitter receptors, as they are coexpressed in many taste neurons (Thorne et al. 2004; Wang et al. 2004b); however, in the larva, no coexpression is observed for Gr32a and Gr66a (Colomb et al. 2007; Scott et al. 2001). Interestingly, Gr2la, which mediates $\mathrm{CO}_{2}$ responses in adults (see earlier), is expressed in neurons of the terminal organ that are necessary for the behavioural response to $\mathrm{CO}_{2}$ (Faucher et al. 2006). Remarkably also, several Or-Gal4 lines (Or30a, Or42a, Or49a, Or63a) label neurons in both dorsal and terminal organs (Fishilevich et al. 2005; Kreher et al. 2005; Scott et al. 2001). However, whether the Gal4 expression patterns in the terminal organ faithfully reflect gene expression has to be verified.

Regarding salt processing, one member of the $p p k$ gene family ( $p p k 11)$ is exclusively expressed in three pairs of neurons of the terminal organ and is necessary 
for the appetitive behavioural responses to low salt, but is dispensable for the aversive responses to high salt (Liu et al. 2003a). An involvement of ppk genes for aversive responses to high salt in the larva, as suggested by Liu et al. (2003a) regarding ppk19, must remain tentative, however, as Colomb et al. (2007) did not find ppk19 expression in the larva.

Similar to the situation in adult flies, taste information is sent to multiple areas in the suboesophageal ganglion (Fig. 1). Four major target subregions have been identified via single-cell labelling in various Gal4 driver lines (Colomb et al. 2007; Scott et al. 2001). They seem to be correlated primarily with the nerve through which the afferents travel and less with the $G r$ gene expressed. Consequently, as in the adult, neurons in different sense organs but expressing the same gene, for example Gr2a, may have different central targets (Colomb et al. 2007; Scott et al. 2001). Gustatory afferents from external sense organs, such as those from the terminal organ labelled by Gr66a-Gal4 (Scott et al. 2001), generally establish ipsilateral projections, in contrast to the bilateral Gr66a projections in the adult. Afferents involved in attractive responses (Heimbeck et al. 1999) were suggested to project to a region slightly different from the four subregions mentioned (Colomb et al. 2007). Moreover, the neuron from the terminal organ expressing Gr2la (see earlier; Faucher et al. 2006) appears to have its own, specific suboesophageal target region (Colomb et al. 2007). Interestingly, the neurons of the terminal organ expressing Or30a-Gal4, Or $42 a$-Gal4 and Or49a-Gal4 project into the suboesophageal ganglion rather than the antennal lobe (Fishilevich et al. 2005; Kreher et al. 2005).

Little information is available about potential target neurons of larval taste afferents. Intriguing candidates are a set of 20 neurons in the suboesophageal ganglion that express the hugin gene (Bader et al. 2007; Melcher and Pankratz 2005). They establish dendritic arborizations that partially overlap with the terminals of taste receptor neurons (Bader et al. 2007; Colomb et al. 2007) and send processes to the protocerebrum, the ventral nerve cord, the ring gland and the pharyngeal apparatus. In adults, blocking synaptic output from hugin neurons increases feeding. Hence, these interneurons may integrate taste processing, the endocrine system, higher-order brain centres and motor output in order to modify feeding. Also, octopaminergic interneurons receiving their input in the soboesopaheal ganglion are suspects for receiving appetitive gustatory input and then distributing an internal reward signal to the brain (see the discussion later).

\section{Associating Smell and Taste}

Why learn? Well, it does not hurt, and may even help. In other words, associative plasticity is a basic feature of nervous systems: Activity-dependent, associative mechanisms are engaged in developmental processes and thus are at disposal for behaviour control. Further, being able to use past experience to predict the future is an obvious advantage, for example when it comes to predicting food.

We discuss associative, Pavlovian learning between odours and food reward in Drosophila. We argue that flies (just like insects in general) posses a discrete side 
branch in their olfactory pathway to accommodate experience-dependent changes in olfactory behaviour. This side branch diverts from the antennal lobes and forms a loop via the so-called mushroom bodies towards premotor centres. These centres thus receive both direct and indirect olfactory input (from antennal lobes and mushroom bodies, respectively) to organize behaviour. We review what is known about this system in larval and adult Drosophila.

\subsection{Adult Drosophila}

In their seminal 1974 study, Quinn et al. (1974) showed that adult Drosophila can be differentially conditioned to odours. The initial version of the experiment was later (Tully and Quinn 1985) simplified into a purely Pavlovian conditioning paradigm: flies receive electric shock in the presence of one odour, and subsequently are exposed to another odour without shock (to average-out non-associative as well as odour-specific effects, the chemical identity of the odours is reversed in a reciprocally trained set of flies). In a final choice test, flies avoid the previously punished over the previously non-punished odour (Fig. 4). This paradigm is used for integrative analyses of learning and memory (reviewed in Davis 2005; Gerber et al. 2004; Heisenberg 2003; Heisenberg and Gerber in press; Keene and Waddell 2007; Margulies et al. 2005; McGuire et al. 2005; Zars 2000). In a pioneering study (Dudai et al. 1976), 'learning mutants' were found with this kind of assay, including mutants in the dunce (CG 32498, dnc $c^{l}$ ) and rutabaga (CG 9533, rut ${ }^{\prime}$ ) genes, marking the discovery of the role of the cyclic AMP/protein kinase A (cAMP/PKA) cascade for associative learning, which was later confirmed in vertebrates as well. Subsequently, a plethora of further mutants were characterized as impaired in this kind of task (reviewed in Davis 2005; Keene and Waddell 2007; McGuire et al. 2005), again providing educated guesses for research in vertebrates.

Importantly for the current purpose, Tempel and co-workers (1983) showed that an appetitive version of the paradigm is possible as well, using sugar as a reward (Fig. 4); however, this appetitive version of olfactory learning had received considerably less attention until recently (Keene et al. 2006; Kim et al. 2007; Krashes et al. 2007; Schwaerzel et al. 2003; Schwaerzel et al. 2007; Thum et al. 2007), rendering the focus of the current review timely. In the following we want to ask how appetitive learning works in adult flies, comparing the underlying mechanisms with the ones known for aversive learning.

\subsubsection{Bridging the Gap}

As detailed already, the olfactory system conveys odour information initially to the antennal lobe and then further via the projection neurons to the lateral horn and the mushroom bodies. From both these centres, premotor commands are thought to originate. The gustatory system, in contrast, carries sugar information to the suboesophageal ganglion, from where premotor commands likely can be triggered 

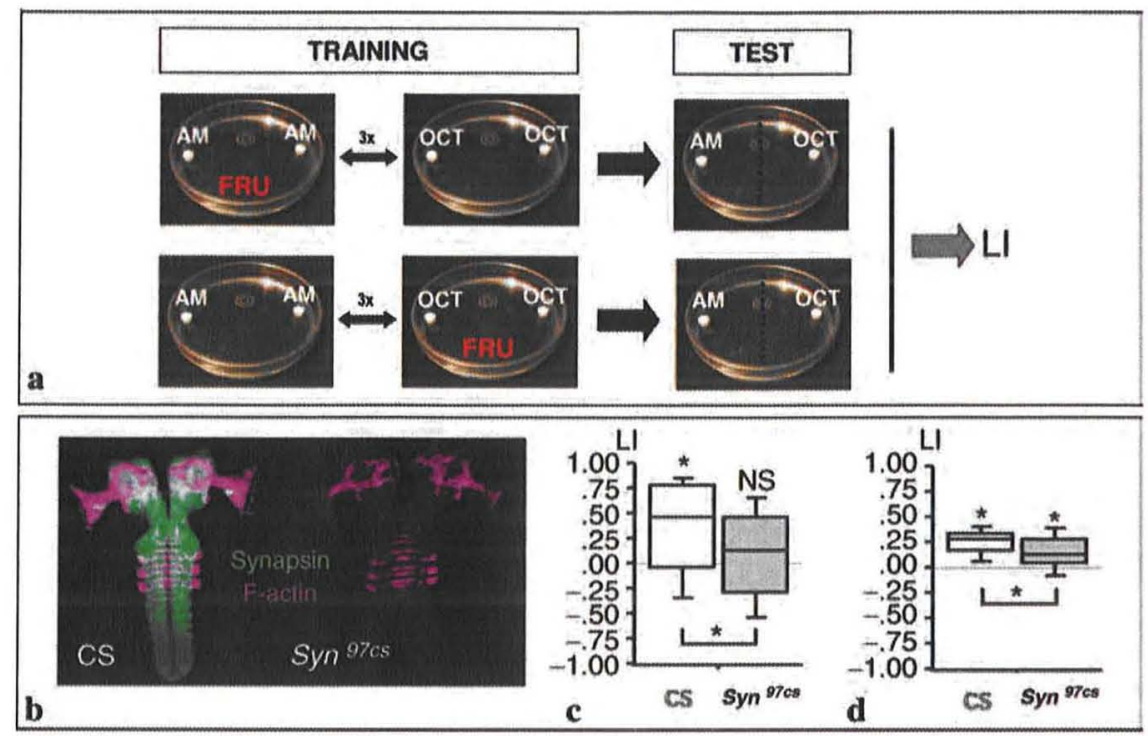

Fig. 5 Olfactory learning in larval Drosophila. a Learning experiments in larval Drosophila use agarose-filled Petri dishes. The agarose can be torn to reward (by adding fructose) or punishment (by adding high-concentration sodium chloride or quinine). Odours are supplied by evaporation from small, perforated Teflon containers. A two-group, reciprocal training design is used (Scherer et al. 2003). In one of the groups, isoamylacetate (AM) is presented with sugar reward (+) and alternately 1-octanol (OCT) is presented either without any reinforcer (as in this figure, $\mathrm{AM}+$ I OCT) or with high-concentration salt or quinine as punishment. The other group receives reciprocal training (AM/OCT + ). Subsequently, animals are tested for their choice between AM versus OCT. Relatively higher preferences for $\mathrm{AM}$ after $\mathrm{AM}+/ \mathrm{OCT}$ training than after $\mathrm{AM} / \mathrm{OCT}+$ training reflect associative learning and can be expressed as a learning index. b Antibody staining reveals localization of synapsin throughout the neuropile regions of the brain in the wild-type CS strain (green), and total absence of synapsin in the deletion mutant $\operatorname{syn}^{97 C 5}$; both strains were outcrossed for 13 generations to effectively adjust genetic background. The frontal two brain hemispheres are to the top, the caudal ventral nerve cord is to the bottom. In magenta, F-actin is labelled by phalloidin to orient within the preparations; towards the top one can discern the F-actin-rich fibre bundles of the developing adult eyes. $\mathbf{c}, \mathbf{d}$ In two independent experiments, $s y n^{97 C s}$ show a reduction of appetitive learning scores by approximately $50 \%$. In c, larvae are tested individually, whereas in $\mathbf{d}$ larvae are tested in cohorts of 30; clearly, scores are not higher when testing cohortwise (arguing against a stamped effect), but scatter is much reduced. Control experiments testing for sensory or motor defects have revealed no difference between $s y n^{97 c s}$ and the wild-type CS strain (see the text and Michels et al. 2005). Box plots represent the median as the middle line and 25,75 as well as 10, $90 \%$ quantiles as box boundaries and whiskers, respectively. (a, b Copyright B. Michels, Universität Würzburg. c, d From Michels et al. 2005, copyright Cold Spring Harbor Laboratory Press)

directly. Thus, gustatory information seems to bypass the brain proper and to not converge directly with the olfactory pathway. How, then, can an association of smell and taste ever come about? Does the insect brain contain neurons to short-circuit smell and taste?

Indeed, Hammer (1993) in the honeybee identified the so-called VUM ${ }_{\text {mxI }}$ neuron; the cell body of this unpaired neuron is positioned in the maxillary segment of the 
suboesophageal ganglion, ventrally near the midline. It likely receives input in the suboesophageal ganglion and provides output to the antennal lobe, the mushroom body calyx and the lateral horn. Sucrose application to the antennae and proboscis, which elicits the proboscis-extension feeding reflex, drives this neuron; however, driving this neuron does not elicit the feeding reflex. Strikingly, if an odour is presented together with an activation of $\mathrm{VUM}_{\text {mx }}$, bees learn appetitively about that odour (Hammer 1993). Thus, the $\mathrm{VUM}_{\mathrm{mx} 1}$ neuron is not sufficient to substitute for sugar, as its activation does not trigger the feeding reflex; rather it is specifically sufficient to mediate the rewarding function of sugar, i.e. its role as something 'good'.

In Drosophila, both in the adult and in the larva, such a VUM ${ }_{m \times 1}$ neuron is present as well (H. Tanimoto, Universität Würzburg, and A. Thum, Université Fribourg, respectively; personal communications). As in the honeybee, it is located medioventrally at the midline and innervates the suboesophageal ganglion, the antennal lobe, the mushroom body calyx and the lateral horn. It is part of a cluster of ventral unpaired median neurons, which also in the fly likely are octopaminergic (Sinakevitch and Strausfeld 2006). Adult flies lacking octopamine (owing to a lack of the synthesizing enzyme tyramine $\beta$-hydroxylase, CG 1543 , in the $T \beta H^{M 18}$ mutant) are impaired in odour-sugar learning, but not in odour-shock learning (Schwaerzel et al. 2003). In the larva, driving octopaminergic/tyraminergic neurons as covered by the $T D C$ Gal4 line (Cole et al. 2005) can reportedly substitute for the sugar reward in olfactory learning (Schroll et al. 2006); whether the $\mathrm{VUM}_{\mathrm{mxl}}$ neuron as an individual neuron can also in Drosophila mediate this appetitively reinforcing function is as yet unknown. If this were so, the target areas of the $\mathrm{VUM}_{\mathrm{mx} 1}$ neuron, namely the antennal lobe, the mushroom bodies and the lateral horn, would be prime suspects for housing memory traces for odour-sugar learning in Drosophila.

\subsubsection{Interplay: Localizing Memory Traces?}

Is it possible to localize memory? No. This is because having a memory is a psychological property of a person, or an animal, as a whole. In other words, as brains do not have memories, one cannot localize them in the brain. However, maybe one can localize those neuronal changes necessary and sufficient for a particular change in behaviour? Thus, the trick is to not try to localize a psychological process ('memory'), but the substrate of its behaviour corollary (the 'memory trace').

In adult Drosophila, the mushroom bodies arguably are the site of the short-term odour-shock associative memory trace (reviewed in Gerber et al. 2004; Heisenberg 2003; Heisenberg and Gerber in press). The working model is that whenever the activation of a Kenyon cell, as part of the pattern of Kenyon cells activated by a given odour, coincides with a shock-triggered, likely dopaminergic, reinforcement signal impinging onto the Kenyon cells, future output from this Kenyon cell (and from its concomitantly activated fellow Kenyon cells) onto mushroom body output neurons is modulated. This modulated output then is thought to mediate future conditioned avoidance in response to the odour. Which data are the bases for this working model? (for a detailed discussion of two recent functional imaging studies by Yu et al. 2004, 2005, see Heisenberg and Gerber in press): 
1. Proteins required for synaptic plasticity, such as the type I adenylate cyclase coded for by the rutabaga gene (CG 9533, rut), are preferentially expressed in the mushroom bodies (Crittenden et al. 1998). This cyclase is required for cAMP production in neurons and can be activated by both G-proteins and the $\mathrm{Ca}^{2+} /$ calmodulin signalling cascade (Han et al. 1992; Levin et al. 1992); importantly, in vitro studies suggest that only a simultaneous activation by both these mechanisms leads to overadditive cAMP production (Abrams et al. 1998; Dudai et al. 1988). Given that Kenyon cell activation by odours leads to $\mathrm{Ca}^{2+}$ influx (Wang et al. 2004a), and that shock application likely leads to the activation of G-protein-coupled dopamine receptors (Han et al. 1996; Kim et al. 2003; Schwaerzel et al. 2003; Riemensperger et al. 2005; Schroll et al. 2006; reviewed in Blenau and Baumann 2001), this cyclase could act to molecularly detect the coincidence of odour and shock to then trigger the cAMP/PKA cascade. Consistent with such a role of the cyclase, mutations in the rutabaga gene $\left(r u t^{l}, r u t^{2080}, r u t^{2769}\right)$ entail learning defects in all associative learning tasks reported to date (Duerr and Quinn 1982; Liu et al. 2006; Perisse et al. 2007; Tempel et al. 1983; Wustmann et al. 1996). Notably, restoring the cyclase in the mushroom bodies restores odour-shock learning (Mao et al. 2004; McGuire et al. 2003; Zars et al. 2000), but does not restore learning in other tasks such as visual pattern learning (Liu et al. 2006). Pattern learning, however, can be rescued by restoring the cyclase in the central complex (Liu et al. 2006). Central complex expression, in turn, does not appear to rescue odour-shock learning (Zars et al. 2000). Also, cyclase expression in the projection neurons does not rescue odour-shock learning (Thum et al. 2007). Importantly, the cyclase seems to act acutely during the learning process, as acute expression is sufficient to rescue learning, arguing against a purely developmental role of the cyclase for establishing a properly functioning mushroom body (McGuire et al. 2003).

2. Connolly et al. (1996) transgenically expressed a mutant $G_{\alpha s}$ protein (CG 2835, using the $G_{\alpha s}{ }^{*}$ mutant) in the mushroom bodies which constitutively activates the cyclase, hence presumably rendering any modulation of cyclase activity impaired. This leads to an abolishment of memory scores after odour-shock learning. Whether a knockdown of the rut-cyclase by means of RNA interference would lead to a similar abolishment of short-term odour-shock memory is unknown.

3. Three groups independently found that output from chemical synapses of the mushroom body is required at test, but is dispensable during training (Dubnau et al. 2001; McGuire et al. 2001; Schwaerzel et al. 2002). If output from the projection neurons is blocked during training, however, flies cannot establish an odour-shock memory trace (Schwaerzel, 2003).

4. Dopaminergic neurons innervating the mushroom bodies are activated by shock (Riemensperger et al. 2005), and blocking synaptic output from dopaminergic neurons as part of the $\mathrm{TH}$-Gal4 pattern prevents acquisition but not retrieval of odour-shock memory (Friggi-Grelin et al. 2003; Schwaerzel et al. 2003).

Thus, synaptic plasticity in the mushroom bodies is sufficient (rut-rescue) and necessary $\left(G_{\alpha s}{ }^{*}\right)$ to establish a short-term memory trace during odour-shock training. Furthermore, olfactory information needs to enter the mushroom bodies during 
training but does not have to leave them; during test, in turn, both input to and output from the mushroom bodies is required to support normal memory scores. Reinforcement signalling through dopaminergic neurons, on the other hand, seems to be required only during training, but not at test. With due caveats in mind (Gerber et al. 2004; Heisenberg 2003; Heisenberg and Gerber in press), it therefore seems a reasonable working hypothesis that the short-term memory trace for odour-shock learning is located in the mushroom bodies. Does this also apply for odour-sugar learning?

\subsubsection{Odour-Sugar Learning}

A first hint towards a role of the mushroom bodies for appetitive learning was provided by the mushroom body deranged mutant ( $m b d$; no CG number can as yet be assigned to the affected gene; Heisenberg et al. 1985): olfactory learning is abolished in adult $m b d$ mutants, regardless of whether shock or sugar reinforcement is used. Recently, analyses of memory trace localization for odour-sugar learning are being pursued more systematically (Schwaerzel et al. 2003; Thum et al. 2007). Transgenic expression of the rutabaga adenylate cyclase in the mushroom bodies is sufficient to rescue the sugar-learning defect of the rutabaga mutant ( $r u t^{2080}$; Schwaerzel et al. 2003); this is also the case for an acute expression in the mushroom body (Thum et al. 2007). Furthermore, if output from the mushroom body is possible during training but blocked at test, flies show no appetitive olfactory memory score (Schwaerzel et al. 2003). If, however, mushroom body output is blocked during training, but is possible at test, flies show normal learning scores (Schwaerzel et al. 2003). Thus, all odoursugar memory trace(s) must be located upstream of mushroom body output and require processing through the mushroom body for retrieval; one such memory trace, as addressed by rut function, is located within the mushroom bodies themselves. This situation matches the findings for odour-shock learning.

However, research on honeybees suggests that the antennal lobes may house a memory trace for odour-sugar associations as well (Erber et al. 1980; Faber et al. 1999; Farooqui et al. 2003; Hammer and Menzel 1998; but see Peele et al. 2006). This prompted the question of whether acute expression of the rut-cyclase in the projection neurons of rut mutants $\left(r u t^{2080}\right)$ would restore learning performance; this is indeed the case (Thum et al. 2007) (Fig. 4)! Does this prove that there are two fully redundant memory traces in projection neurons and mushroom bodies? Such a conclusion would require showing that expression of the constitutively active $G_{\alpha s}{ }^{*}$ protein, or knockdown of the cyclase, in either the projection neurons or the mushroom bodies does not affect reward learning. Also, a block of input towards the mushroom bodies during training, e.g. by a temperature-sensitive, dominant-negative acetylcholine receptor, should leave appetitive memory scores unaffected but should abolish aversive learning. Finally, testing whether the projectionneuron versus mushroom-body memory traces are different in terms of their specificity and/or their role during the various phases of memory (for the situation in honeybees, see Hammer and Menzel 1998) now is warranted. 


\subsubsection{Longer-Term Appetitive Memory}

For sugar-reward learning, relatively little is known about the organization of longerterm memory (for reviews concerning longer-term memory of aversive memories, see McGuire et al. 2005; Keene and Waddell 2007; but see the recent account by Krashes and Waddell 2008). Mutants in the amnesiac gene (CG 11937, $a m n^{\prime}$ and $a m n^{X}$ ) have no substantial defect in short-term memory after appetitive learning; a memory impairment, however, becomes particularly prominent for longer (more than $60 \mathrm{~min}$ ) retention intervals (Keene et al. 2006; Waddell et al. 2000). This defect can be rescued by transgenic expression of the amnesiac-encoded protein in the dorsal paired median (DPM) neurons (Tamura et al. 2003; Waddell et al. 2000). Drosophila posses one such neuron per hemisphere, large neurons innervating the mushroom body lobes in a mesh-like way (Waddell et al. 2000). They receive input from, and provide output to, the mushroom bodies. If output from these neurons is blocked, appetitive short-term memory is unaffected, regardless of when the block is induced; this is consistent with the lack of phenotype of amn mutants (amn'; $a m n^{X 8}$ ) in this regard. Strikingly, however, if output from the DPM neurons is transiently blocked during the break between training and a longer-term (3-h) retention test, memory scores are reduced; this is true both for sugar learning and for shock learning (Keene et al. 2006). Also, for retention $3 \mathrm{~h}$ after training, output from the DPM neurons at the moment of test is dispensable for both appetitive and aversive memory retrieval (Keene et al. 2006). Thus, it seems that off-line processing along a mushroom body-DPM neuron-mushroom body loop is required to support 3-h memory. If this were so, then certainly one would predict that blocking output from the mushroom bodies towards the DPM neurons during the retention period should affect 3-h-memory - as is indeed the case for both appetitive and aversive longerterm memory (for a more detailed account, see Keene and Waddell, 2007). Thus, the situation regarding the role of amn in aversive learning is strikingly similar to what has been mentioned here for appetitive learning (Keene et al. 2004; Keene et al. 2006; Waddell et al. 2000).

In summary, appetitive and aversive olfactory learning are similar in terms of the involvement of the PKA/cAMP cascade as addressed by adenylate cyclase function; also, for both kinds of paradigm, a short-term memory trace is localized in the mushroom bodies. Finally, the similar role of the mushroom body-DPM neuron-mushroom body loop for stabilizing both appetitive and aversive longer-term memories is particularly noteworthy. However, as the mushroom body houses both an appetitive and the aversive memory trace for short-term retention, how can similar molecular mechanisms (the PKA/cAMP cascade) in the same set of neurons establish different memories (appetitive versus aversive)? Interestingly, Schwaerzel et al. 2007 showed that a specific pool of PKA-RII (CG 15862, defining the A kinase-anchoring protein anchored pool of PKA) is required for aversive learning, but is dispensable for appetitive learning. This suggests that different memory traces within the same cell may use the same molecular pathway, but at different subcellular compartments.

In any event, also at other levels there are major dissociations between appetitive and aversive olfactory learning. Before discussing these dissociations, however, one 
should mention that for appetitive learning flies have to be starved before the experiment, whereas such starvation is neither necessary nor is usually performed for aversive learning; thus, discrepancies between appetitive and aversive learning may in part result from differences in motivational state. With this caveat in mind, the major discrepancies between both kinds of learning appear to be

- Appetitive but not aversive training establishes an additional short-term memory trace in the projection neurons.

- Regarding the short-term memory domain, either dopamine or octopamine is necessary and sufficient for reinforcement in aversive and appetitive learning, respectively [Schroll et al. 2007; Schwaerzel et al. 2003; but see Kim et al. 2007 regarding a common role of the D1-like dopamine receptor gene (CG 9652 coding for dumb1 and dumb2)].

- Memory scores for odour-shock learning decay characteristically faster than for odour-sugar learning (Tempel et al. 1983) and

- initial retention (less than $5 \mathrm{~min}$ ) of aversive but not of appetitive memory reportedly is impaired in the dunce mutant (CG 32498, using the $d n c^{1}$ allel) (Tempel et al. 1983).

\subsection{Larval Drosophila}

The taste and smell systems of larvae are much reduced in terms of cell number as compared with adults, but by and large follow the same functional architecture (Fig. 1). But do larvae also show the same potency for learning as adults do, and if so, are the same molecular processes and the same sets of cells involved? As will be argued below, the shared characters to us appear to outweigh the discrepancies.

Learning experiments are performed with larvae crawling on an agarose surface in standard Petri dishes. In the pioneering studies of Aceves-Pina and Quinn (1979), Tully et al. (1994) and Heisenberg et al. (1985), electric shock was used as an aversive reinforcer (but see Forbes 1993 for a failure to replicate these results). Here, we review the more recent literature using gustatory reinforcement. That is, the agarose can be torn to reward (by adding sugar) or punishment (by adding high-concentration salt or bitter) for association with odours (isoamylacetate, AM; or 1-octanol, OCT) evaporating from custom-made odorant containers (Fig. 5). As in adult flies, a two-group, reciprocal experimental design is used (Scherer et al. 2003); experimental designs which do not use reciprocal training (Honjo and Furukubo-Tokunaga 2005) confound associative and non-associative effects and therefore are not reviewed here (for a detailed discussion, see Gerber and Stocker 2007).

\subsubsection{Appetitive Learning}

Employing a reward-only paradigm (AM+/OCT and AM/OCT + ), Neuser et al. (2005) showed that learning success increases with the number of learning trials 
and reaches an asymptote after three trials each with the rewarded and the unrewarded odour. Learning scores increase with reward strength, $2 \mathrm{M}$ fructose supporting asymptotic levels of learning (see also Schipanski et al. 2008). The ensuing memory is stable for at least $30 \mathrm{~min}$; after $90 \mathrm{~min}$, there is no measurable learning effect left. In addition, there does not appear to be any effect of larval gender or age, although regarding age one may notice a trend for best scores at an intermediate larval age (5 days after egg laying, as compared with 4 and 6 days).

In the tradition of the olfactory learning experiments in adult flies, larval learning experiments had initially been performed in darkness (i.e. using red light, which does not allow for vision in Drosophila), but as Yarali et al. (2007) reported, these experiments work just as well under normal illumination conditions; even changes of visual context between training and test leave olfactory memory scores unaffected. Finally, an en mass version of the assay is possible, such that animals are trained and tested in groups of 30; under such conditions, learning scores are not higher than in the individual-animal version (arguing against a stampede effect), but the scatter of the data is reduced (Neuser et al. 2005).

What is known about the genetic and cellular bases of appetitive learning in the larva? Four recent studies offer the first hints, but before going into detail, we would like to briefly discuss the kinds of behavioural control procedures for 'learning mutants' (for a more detailed discussion, see Gerber and Stocker 2007). That is, one may wonder whether the mutant is able to taste, to smell, and whether it can crawl fast enough during the test to move among the sources of the different odours in the allotted time (typically $3 \mathrm{~min}$ ). For odour-sugar learning, one therefore often compares naïve animals from the different genotypes in terms of (1) their preference between the fructose reward and plain agarose, (2) their preference between an AM-scented and an unscented control side as well as (3) their preference between an OCT and a control side. However, a learning defect, logically, can only be detected after training, i.e. after animals had undergone extensive handling, exposure to reinforcers and exposure to odours. Thus, one may in addition want to test for those olfactory and motor abilities that the mutants need at the very moment of test. In other words, can the larvae still respond to odour after 'sham training' that involves the same handling and general procedure as for training, but (1) omits the reinforcer, exposing the larvae to only the odours, and (2) omits the odours, exposing the larvae to only the reinforcer? Finally, in some cases, the mutation in question may entail a developmental delay; to the extent to which developmental stage matters for learning, one may therefore want to allow the mutant more time for development so that it can mature to the same stage as the wild type.

Michels et al. (2005) investigated the role of the synapsin gene (CG 3985, syn), the single fly homolog of the vertebrate synapsin genes. Synapsin is a brain-wide-expressed, evolutionarily conserved presynaptic phosphoprotein (Godenschwege et al. 2004; Hilfiker et al. 1999; Klagges et al. 1996). It is associated with the cytoskeleton and the cytoplasmic side of synaptic vesicles and regulates the balance between the readily releasable versus the reserve pool of vesicles in a phosphorylationdependent way, thus contributing to the regulation of synaptic output. Mutations in the human synapsin 1 gene can cause seizures and, in a subset of patients, learning 
defects (Garcia et al. 2004; see also Gitler et al. 2004 for similar phenotypes in mice), and psychotic symptoms (Chen et al. 2004). In Drosophila, the syn ${ }^{97 C S}$ deletion mutant (Godenschwege et al. 2004) lacks the synapsin protein and shows a reduction in learning ability by about $50 \%$ as compared with an effectively isogenized (13 generations) wild-type control strain (Fig. 5) (Michels et al. 2005). This phenotype is not due to an impairment of those sensory and motor skills required in the learning paradigm, as both naïve responses towards the odours and to the reward as well as odour responses after 'sham training' are indistinguishable between $s y n^{97 C S}$ and wild-type control (Michels et al. 2005).

A second paper focused on the foraging gene (CG 10033, for) (Kaun et al. 2007). This gene shows a polymorphism which seems to underlie a behavioural polymorphism: while in the absence of food locomotion is the same for both kinds of genotype, in the presence of food larvae carrying the so-called sitter (for-s) allele forage largely within their food patch, whereas larvae with the rover (for-r) allele move between patches. Arguably, either of these strategies may be beneficial, depending on the spatial and temporal distribution of food sources. The for gene codes for a protein kinase G, and sitters and rovers indeed differ in protein kinase $G$ activity (low for sitter and high for rover; Osborne et al. 1997). Kaun et al. (2007) reported that larvae carrying either allele do not differ in visual learning (Gerber et al. 2004), but do differ in olfactory learning, such that rover larvae show higher initial, but lower later retention. It thus seems as if rovers learn and forget faster than sitters; naïve responsiveness to odours as well as to the reward, however, do not differ between them. Notably, the reduced initial learning scores in sitters can be increased to rover levels by boosting expression of the protein kinase $\mathrm{G}$ in the mushroom bodies (driver strains 201Y-Gal4, H24Gal4, and c739-Gal4); whether this would also lead to rover-like small learning scores at later retention intervals is not known.

Thirdly, two papers focused on the function of the neurexin gene. In vertebrates (Dean and Dresbach 2006), neurexins are found to be presynaptic transmembrane proteins. Together with their postsynaptic binding partners of the neurolignin protein family, they act to induce and maintain synaptic contacts, and to organize the molecular machinery at active zone and postsynaptic density, respectively. Zeng et al. (2007) and Li et al. (2007) now report that in Drosophila there is but one homolog to the vertebrate neurexin genes (CG 7050, dnrx), which is expressed throughout the neuropile regions of the larval and adult brains. Specifically, some overlap of immunostaining for the neurexin protein with the active zone protein bruchpilot (CG 34146, brp; Kittel et al. 2006; Wagh et al. 2006) but not with a marker of the postsynaptic density (Drosophila p21-activated kinase, encoded by CG 10295 , dpak; Sone et al. 2000) may suggest a presynaptic localization at the neuromuscular junction (Li et al. 2007). Regarding learning, Zeng et al. (2007) reported that while learning was intact in their genetic control strain (white ${ }^{1118}$, which also had been used for five generations of outcrossing with the mutant), a lack of the neurexin protein in the deletion mutant $n r x-1^{\Delta 83}$ entails a complete abolishment of learning. This phenotype is not due to an impairment of those sensory and motor skills required in the learning paradigm, as responses to the odours and the reward in 
naïve animals, as well as odour responses after 'sham training', are normal. Furthermore, the learning defect can at least partially be rescued by spatially extended transgenic expression of neurexin (elav-Gal4 driver strain).

Fourthly, Knight et al. (2007) investigated the effect of deleting the presenilin gene (CG 18803, psn; Boulianne et al. 1997) on both visual and olfactory learning, using the individual-animal version of the assay and employing differential conditioning with appetitive-aversive reinforcement. In the deletion mutant $p s n^{\text {W6 }}$, the presenilin protein is absent, and in a study nicely controlled for developmental delay, the authors found that both olfactory and visual learning are completely abolished. The white ${ }^{I 118}$ strain, which serves as genetic control (and which had been used for five generations of outcrossing), performs fine in both tasks. Responsiveness of naïve animals towards the reinforcers and towards the odours is the same between both genotypes; in the case of olfactory learning, performance can at least partially be restored by using spatially extensive transgenic expression of presenilin (elav-Gal4 driver strain). These findings may contribute to an understanding of Alzheimer disease, provided the relation between presenilin function and familial Alzheimer disease is resolved (see the discussion in De Strooper 2007; Wolfe 2007); such analyses may profit from the fact that there is but one presenilin gene in flies, and that the amyloid $\beta$ peptide, to the best of current knowledge, is absent in the fly. Notably, Knight et al. (2007) discussed that, different from the situation in vertebrates, the site of action for presenilin in the fly may be presynaptic. Indeed, it seems noteworthy that three of these four reviewed studies suggest presynaptic mechanisms of plasticity (synapsin, neurexin, presenilin). This is in accordance with a working model proposed for aversive learning in the adult by Heisenberg (2003) which suggests a presynaptic modification of the mushroom body output synapses to underlie short-term associative changes in olfactory behaviour. In the larva, the critical experiments to identify the cells and subcellular site(s) of action for all these three genes remain to be done.

\subsubsection{Aversive Learning}

Initially, Hendel et al. (2005) suggested that memory was exclusively due to reward, because reward-only but not punishment-only training - using either highconcentration salt or quinine - yields learning effects. Moreover, learning indices after reward-only training are as high as after reward-punishment training. However, larvae do show aversion to high-concentration salt and quinine, and both suppress feeding. Thus, high-concentration salt and quinine, although aversive, did not seem to have any effect as reinforcers. Educatively, this turned out to be wrong:

Both salt and quinine actually are effective as reinforcers, but the respective memories are not automatically expressed in behaviour (Gerber and Hendel 2006). That is, behaviours are expressed if their outcomes offer a benefit (Dickinson 2001; Elsner and Hommel 2001; Hoffmann 2003). Consider that after training with sugar, the test offers the larvae a choice with one odour suggesting 'over there you will find sugar' and the other suggesting 'over there you will not find sugar'. In the absence of sugar, larvae should thus search for the predicted reward. If sugar already is 
present, however, such a search does not offer any improvement and would not seem warranted. In contrast, after aversive training, one odour may suggest 'over there you will suffer from quinine' whereas the alternative suggests 'over there you will not suffer from quinine'. In the presence of quinine, therefore, the no-quinine-associated odour can give direction to the escape from the aversive reinforcer, while if quinine actually is absent, such a flight response is not warranted to begin with. And this is indeed what is found (Gerber and Hendel 2006). In other words, the behavioural expression of memory is not an automated, but is a regulated process. First, irrespective of the test situation, the odour activates its memory trace. In a second, previously unrecognized evaluative step a comparison is made between the value of this memory trace and the value of the test situation. Only if the value of the memory trace is higher than that of the test situation, tracking down the odour can be expected to improve the situation. It is this expectation of outcome, rather than the activated memory trace per se, which drives conditioned behaviour.

\subsection{3 'Remote Control' of Reinforcement}

As discussed earlier, olfactory projections target the brain before projecting to motor centres, whereas taste information remains suboesophageal and bypasses the central brain, being transmitted more directly to motor systems. Given that there does not seem to be any convergence between olfactory and taste processing, one may ask how odours can be associated with gustatory reinforcement.

As in adult flies, the solution likely is provided by aminergic interneurons which receive input in the suboesophageal ganglion and provide output to the brain, establishing a short circuit between olfactory and gustatory processing. Specifically, the function of dopaminergic and octopamineric/tyraminergic neurons in the Drosophila larva has lately been addressed by remote-controlling neurons (Schroll et al. 2006). With the Gal4/UAS system, the blue-light-gated ion channel channelrhodopsin-2 is expressed in octopaminergic/tyraminergic cells (as covered by $T D C$-Gal4). Owing to the transparency of the larval cuticle, these cells can then non-invasively be driven by switching on the blue light. If light stimulation is paired with one odour, and another odour is presented in darkness, the larvae will subsequently prefer the former, 'virtually' rewarded odour. Thus, light-induced activation of octopaminergic/ tyraminergic neurons is sufficient to substitute for appetitive reinforcement (but see Schipanski, 2007 for a failure to replicate these results). In turn, associatively driving dopaminergic neurons (as covered by $\mathrm{TH}$-Gal4) reportedly induces aversive learning. The necessity of these neurons for appetitive and aversive learning, respectively, is at present unclear.

\section{Outlook}

It seems that chemosensation and chemosensory learning in Drosophila are beginning to be understood fairly well, in particular in the genuinely sensory aspects, and in terms of odour-taste memory trace formation. The remaining terra 
incognita, we believe, is how sensory and motor processing formats are integrated, and how adaptive motor patterns are being selected. Only with such an understanding will it be possible to search for the motivating factors of behaviour, the systems which make a Drosophila do what Drosophila's got to do.

Acknowledgements We express cordial thanks to the members and colleagues at our research institutions, and to the students in our groups, for the critique and discussions that shaped this review. Our research programmes are supported by the Volkswagen Foundation, the German-Israeli Foundation and the Deutsche Forschungsgemeinschaft (Heisenberg Fellowship, SFBs 554 and TR 58, GK 1156 to B.G.), by the Swiss National Funds (grants nos. 31-63447.00 and 3100A0105517 to R.F.S. and A.S.T.) and by grants from the Ministry of Education, Culture, Sports, Science and Technology of Japan (to T.T.). E. Balamurugan from the Springer production team deserves our gratitude for extended patience.

\section{References}

Abrams TW, Yovell Y, Onyike CU, Cohen JE, Jarrard, HE (1998) Analysis of sequence-dependent interactions between transient calcium and transmitter stimuli in activating adenylyl cyclase in Aplysia: possible contribution to CS-US sequence requirement during conditioning. Learn Mem 4:496-509

Aceves-Pina EO, Quinn WG (1979) Learning in normal and mutant Drosophila larvae. Science 206:93-96

Ache BW, Young JM (2005) Olfaction: diverse species, conserved principles. Neuron 48:417-430

Awasaki T, Kimura K (1997) Pox-neuro is required for development of chemosensory bristles in Drosophila. J Neurobiol 32:707-721

Bader R, Colomb J, Pankratz B, Schröck A, Stocker RF, Pankratz MJ (2007) Genetic dissection of neural circuit anatomy underlying feeding behavior in Drosophila: distinct classes of hugin expressing neurons. J Comp Neurol 502:848-856

Benton R, Sachse S, Michnick SW, Vosshall LB (2006) Atypical membrane topology and heteromeric function of Drosophila odorant receptors in vivo. PLloS Biol 4:e20.

Benton R, Vannice KS, Vosshall LB (2007) An essential role for a CD36-related receptor in pheromone detection in Drosophila. Nature 450:289-293

Blenau W, Baumann A (2001) Molecular and pharmacological properties of insect biogenic amine receptors: lessons from Drosophila melanogaster and Apis mellifera. Arch Insect Biochem Physiol 48:13-38

Boulianne GL, Livne-Bar I, Humphreys JM, Liang Y, Lin C, Rogaev E, St George-Hyslop, P (1997) Cloning and characterization of the Drosophila presenilin homologue. Neuroreport 8:1025-1029

Buck L, Axel R (1991) A novel multigene family may encode odorant receptors: a molecular basis for odor recognition. Cell 65:175-187

Carle E (1969) The very hungry caterpillar. Penguin, New York

Chen Q, He G, Qin W, Chen QY, Zhao XZ, Duan SW, Liu XM, Feng GY, Xu YF, St Clair D, Li M, Wang JH, Xing YL, Shi JG, He L (2004) Family-based association study of synapsin II and schizophrenia. Am J Hum Genet 75:873-877

Chu IW, Axtell RC (1971) Fine structure of the dorsal organ of the house fly larva, Musca domestica L. Z Zellforsch Mikrosk Anat 117:17-34

Chu-Wang IW, Axtell RC (1972) Fine structure of the terminal organ of the house fly larva, Musca domestica L. Z Zellforsch Mikrosk Anat 127:287-305

Chyb S, Dahanukar A, Wickens A, Carlson, JR (2003) Drosophila Gr5a encodes a taste receptor tuned to trehalose. Proc Natl Acad Sci USA 100:14526-14530

Clyne PJ, Warr CG, Carlson JR (2000) Candidate taste receptors in Drosophila. Science 287:1830-1834 
Clyne PJ, Warr CG, Freeman MR, Lessing D, Kim J, Carlson JR (1999) A novel family of divergent seven-transmembrane proteins: candidate odorant receptors in Drosophila. Neuron 22:327-338 Cobb M (1999) What and how do maggots smell? Biol Rev 74:425-459

Cole SH, Carney GE, McClung CA, Willard SS, Taylor BJ, Hirsh J (2005) Two functional but noncomplementing Drosophila tyrosine decarboxylase genes: distinct roles for neural tyramine and octopamine in female fertility. J Biol Chem 280:14948-14955

Colomb J, Grillenzoni N, Ramaekers A, Stocker RF (2007) Architecture of the primary taste center of Drosophila melanogaster larvae. J Comp Neurol 502:834-847

Connolly JB, Roberts IJ, Armstrong JD, Kaiser K, Forte M, Tully T, O'Kane CJ (1996) Associative learning disrupted by impaired Gs signaling in Drosophila mushroom bodies. Science 274:2104-2107

Couto A, Alenius M, Dickson BJ (2005) Molecular, anatomical, and functional organization of the Drosophila olfactory system. Curr Biol 15:1535-1547

Crittenden JR, Skoulakis EM, Han KA, Kalderon D, Davis RL (1998) Tripartite mushroom body architecture revealed by antigenic markers. Learn Mem 5:38-51

Dahanukar A, Foster K, van der Goes van Naters WM, Carlson JR (2001) A Gr receptor is required for response to the sugar trehalose in taste neurons of Drosophila. Nat Neurosci $4: 1182-1186$

Dahanukar A, Lei Y-T, Kwon JY, Carlson JR (2007) Two Gr genes underlie sugar reception in Drosophila. Neuron 56:503-516

Datta, S.R., Vasconcelos, M.L., Ruta, V., Luo, S., Wong, A., Demir, E., Flores, J., Balonze, K., Dickson, B.J., and Axel, R. (2008). The Drosophila pheromone cVA activates a sexually dimorphic neural circuit. Nature 452, 473-477

Davis RL (2005) Olfactory memory formation in Drosophila: from molecular to systems neuroscience. Annu Rev Neurosci 28:275-302

Dean C, Dresbach T (2006) Neuroligins and neurexins: linking cell adhesion, synapse formation and cognitive function. Trends Neurosci 29:21-29

De Belle JS, Heisenberg M (1994) Associative odor learning in Drosophila abolished by chemical ablation of mushroom bodies. Science 263:692-695

De Bruyne M, Clyne PJ, Carlson JR (1999) Odor coding in a model olfactory organ: the Drosophila maxillary palp. J Neurosci 19:4520-4532

De Bruyne M, Foster K, Carlson JR (2001) Odor coding in the Drosophila antenna. Neuron 30:537-552

De Strooper B (2007) Loss-of-function presenilin mutations in Alzheimer disease. Talking point on the role of presenilin mutations in Alzheimer disease. EMBO Rep 8:141-146

Dethier VG, Hanson FE (1964) Taste papillae of the blowfly. J Cell Comp Physiol 65:93-100

Dickinson A (2001) Causal learning-an associative analysis. Q J Exp Psychol 54B:3-25

Dobritsa AA, van der Goes van Naters W, Warr CG, Steinbrecht RA, Carlson JR (2003) Integrating the molecular and cellular basis of odor coding in the Drosophila antenna. Neuron 37:827-841

Dubnau J, Grady L, Kitamoto T, Tully T (2001) Disruption of neurotransmission in Drosophila mushroom body blocks retrieval but not acquisition of memory. Nature 411:476-480

Dudai Y, Corfas G, Hazvi S (1988) What is the possible contribution of $\mathrm{Ca}^{2+}$-stimulated adenylate cyclase to acquisition, consolidation and retention of an associative olfactory memory in Drosophila. J Comp Physiol [A] 162:101-109

Dudai Y, Jan YN, Byers D, Quinn WG, Benzer S (1976) dunce, a mutant of Drosophila deficient in learning. Proc Natl Acad Sci USA 73:1684-1688

Duerr JS, Quinn WG (1982) Three Drosophila mutations that block associative learning also affect habituation and sensitization. Proc Natl Acad Sci USA 79:3646-3650

Elsner B, Hommel B (2001) Effect anticipation and action control. J Exp Psychol Hum Percept Perform 27:229-240

Erber J, Masuhr TH, Menzel R (1980) Localization of short-term memory in the brain of the bee, Apis mellifera. Physiol Entomol 5:343-358

Faber T, Joerges J, Menzel R (1999) Associative learning modifies neural representations of odors in the insect brain. Nat Neurosci 2:74-78 
Falk R, Bleiseravivi N, Atidia J (1976) Labellar taste organs of Drosophila melanogaster. J Morphol 150:327-341

Farooqui T, Robinson K, Vaessin H, Smith BH (2003) Modulation of early olfactory processing by an octopaminergic reinforcement pathway in the honeybee. J Neurosci 23:5370-5380

Faucher C, Forstreuter M, Hilker M, de Bruyne M (2006) Behavioral responses of Drosophila to biogenic levels of carbon dioxide depend on life-stage, sex and olfactory context. J Exp Biol 209:2739-2748

Ferveur JF (2005) Cuticular hydrocarbons their evolution and roles in Drosophila pheromonal communication. Behav Genet 35:279-295

Feeny P, Rosenberg L, Carter M (1983) Chemical aspects of oviposition behavior in butterflies. In: Ahmad S (ed) Herbivorous insects: host-seeking behavior and mechanisms. Academic Press, New York, pp 27-76

Fiala A, Spall T, Diegelmann S, Eisermann B, Sachse S, Devaud JM, Buchner E, Galizia CG (2002) Genetically expressed cameleon in Drosophila melanogaster is used to visualize olfactory information in projection neurons. Curr Biol 12:1877-1884

Fischler W, Kong P, Marella S, Scott K (2007) The detection of carbonation by the Drosophila gustatory system. Nature 30:1054-1057

Fishilevich E, Domingos AI, Asahina K, Naef F, Vosshall LB, Louis M (2005) Chemotaxis behavior mediated by single larval olfactory neurons in Drosophila. Curr Biol 15:2086-2096

Fishilevich E, Vosshall LB (2005) Genetic and functional subdivision of the Drosophila antennal lobe. Curr Biol 15:1548-1553

Foelix RF, Stocker RF, Steinbrecht RA (1989) Fine structure of a sensory organ in the arista of Drosophila melanogaster and some other dipterans. Cell Tissue Res 258:277-287

Forbes B (1993) Larval learning and memory in Drosophila melanogaster. Diploma Thesis, University of Würzburg

Friggi-Grelin F, Coulom H, Meller M, Gomez D, Hirsh J, Birman S (2003) Targeted gene expression in Drosophila dopaminergic cells using regulatory sequences from tyrosine hydroxylase. J Neurobiol 54:618-627

Fujishiro N, Kijima H, Morita H (1984) Impulse frequency and action potential amplitude in labellar chemosensory neurones of Drosophila melanogaster. J Insect Physiol 30:317-325

Gao Q, Chess A (1999) Identification of candidate Drosophila olfactory receptors from genomic DNA sequence. Genomics 60:31-39

Gao Q, Yuan B, Chess A (2000) Convergent projections of Drosophila olfactory neurons to specific glomeruli in the antennal lobe. Nat Neurosci 3:780-785

Garcia CC, Blair HJ, Seager M, Coulthard A, Tennant S, Buddles M, Curtis A, Goodship JA (2004) Identification of a mutation in synapsin I, a synaptic vesicle protein, in a family with epilepsy. J Med Genet 41:183-186

Gendre N, Lüer K, Friche S, Grillenzoni N, Ramaekers A, A Technau GM, Stocker RF (2004) Integration of complex larval chemosensory organs into the adult nervous system of Drosophila. Development 131:83-92

Gerber B, Hendel T (2006) Outcome expectations drive learned behaviour in larval Drosophila. Proc R Soc Lond B 273:2965-2968

Gerber B, Scherer S, Neuser K, Michels B, Hendel T, Stocker RF, Heisenberg M (2004) Visual learning in individually assayed Drosophila larvae. J Exp Biol 207:179-188

Gerber B, Stocker RF (2007) The Drosophila larva as a model for studying chemosensation and chemosensory learning: a review. Chem Senses 32:65-89

Gerber B, Tanimoto H, Heisenberg M (2004) An engram found? Evaluating the evidence from fruit flies. Curr Opin Neurobiol 14:737-744

Gitler D, Takagishi Y, Feng J, Ren Y, Rodriguiz RM, Wetsel WC, Greengard P, Augustine GJ (2004) Different presynaptic roles of synapsins at excitatory and inhibitory synapses. J Neurosci 24:11368-11380

Godenschwege TA, Reisch D, Diegelmann S, Eberle K, Funk N, Heisenberg M, Hoppe V, Hoppe J, Klagges BRE, Martin JR, Nikitina EA, Putz G, Reifegerste R, Reisch N, Rister J, Schaupp M, Scholz H, Schwärzel M, Werner U, Zars T, Buchner S, Buchner E (2004) Flies lacking all 
synapsins are unexpectedly healthy but are impaired in complex behaviour. Eur $\mathbf{J}$ Neurosci 20:611-622

Goldman AL,van der Goes van Naters W, Lessing D, Warr CG, Carlson JR (2005) Coexpression of two functional odor receptors in one neuron. Neuron 45:661-666

Grillenzoni N, de Vaux V, Meuwly J, Vuichard S, Gendre N, Stocker RF (2007) Role of proneural genes in the formation of the larval olfactory organ of Drosophila. Dev Genes Evol 217:209-219

Ha TS, Smith DP (2006) A pheromone receptor mediates 11-cis-vaccenyl acetate-induced responses in Drosophila. J Neurosci 26:8727-8733

Hallem EA, Carlson JR (2006) Coding of odors by a receptor repertoire. Cell 125:143-160

Hallem EA, Ho MG, Carlson JR (2004) The molecular basis of odor coding in the Drosophila antenna. Cell 117:965-979

Hammer M (1993) An identified neuron mediates the unconditioned stimulus in associative olfactory learning in honeybees. Nature 366:59-63

Hammer M, Menzel R (1998) Multiple sites of associative odor learning as revealed by local brain microinjections of octopamine in honeybees. Learn Mem 5:146-156

Han PL, Levin LR, Reed RR, Davis RL (1992) Preferential expression of the Drosophila rutabaga gene in mushroom bodies, neural centers for learning in insects. Neuron 9:619-627

Han KA, Millar NS, Grotewiel MS, Davis RL (1996) DAMB, a novel dompamine receptor expressed specifically in Drosophila mushroom bodies. Neuron 16(6):1127-1135

Heimbeck G, Bugnon V, Gendre N, Häberlin C, Stocker RF (1999) Smell and taste perception in $D$. melanogaster larva: toxin expression studies in chemosensory neurons. $\mathbf{J}$ Neurosci 19:6599-6609

Heimbeck G, Bugnon V, Gendre N, Keller A, Stocker RF (2001) A central neural circuit for experience-independent olfactory and courtship behavior in Drosophila melanogaster. Proc Natl Acad Sci USA 98:15336-15341

Heisenberg M (2003) Mushroom body memoir: from maps to models. Nat Rev Neurosci 4:266-275

Heisenberg M, Borst A, Wagner S, Byers D (1985) Drosophila mushroom body mutants are deficient in olfactory learning. J Neurogen 2:1-30

Heisenberg M, Gerber B. Behavioral Analysis of Learning and Memory in Drosophila. In R. Menzel (Ed.), Learning Theory and Behavior. Vol. [1] of Learning and Memory: A Comprehensive Reference, 4 vols. (J. Byrne Editor), pp. [549-560] Oxford: Elsevier.

Hendel T, Michels B, Neuser K, Schipanski A, Kaun K, Sokolowski MB, Marohn F, Michel R, Heisenberg M, Gerber B (2005) The carrot, not the stick: appetitive rather than aversive gustatory stimuli support associative olfactory learning in individually assayed Drosophila larvae. J Comp Physiol A 191:265-279

Hildebrand JG, Shepherd G (1997) Mechanisms of olfactory discrimination: converging evidence for common principles across phyla. Annu Rev Neurosci 20:595-631

Hilfiker S, Pieribone VA, Czernik AJ, Kao H-T, Augustine GJ, Greengard P (1999) Synapsins as regulators of neurotransmitter release. Philos Trans R Soc Lond B 354:269-279

Hiroi M, Marion-Poll F, Tanimura T (2002) Differentiated nerve response to sugars among labellar chemosensilla in Drosophila. Zool Sci 19:1009-1018

Hiroi M, Meunier N, Marion-Poll F, Tanimura T (2004) Two antagonistic gustatory receptor neurons responding to sweet-salty and bitter taste in Drosophila. J Neurobiol 61:333-342

Hoare DJ, McCrohan CR, Cobb M (2008) Precise and fuzzy coding by olfactory sensory neurons. J Neurosci 28:9710-9722

Hoffmann J (2003) Anticipatory behavioral control. In: Butz MV, Sigaud O, Gerad P (eds) Anticipatory behavior in adaptive learning systems. Springer, Heidelberg, pp 44-65

Honjo K, Furukubo-Tokunaga K (2005) Induction of cAMP response element-binding proteindependent medium-term memory by appetitive gustatory reinforcement in Drosophila larvae. J Neurosci 25:7905-7913

Inoshita T, Tanimura T (2006) Cellular identification of water gustatory receptor neurons and their central projection pattern in Drosophila. Proc Natl Acad Sci USA 103:1094-1099

Ishimoto H, Tanimura T (2004) Molecular neurophysiology of taste in Drosophila. Cell Mol Life Sci 61:10-18 
Ito K, Awano W, Suzuki K, Hiromi Y, Yamamoto D (1997) The Drosophila mushroom body is a quadruple structure of clonal units each of which contains a virtually identical set of neurones and glial cells. Development 124:761-771

Ito K, Suzuki K, Estes P, Ramaswami M, Yamamoto D, Strausfeld NJ (1998) The organization of extrinsic neurons and their implications in the functional roles of the mushroom bodies in Drosophila melanogaster Meigen. Learn Mem 5:52-77

Jefferis GSXE, Potter CJ, Chan AM, Marin EC, Rohlfing T, Maurer CR Jr, Luo L (2007) Comprehensive maps of Drosophila higher olfactory centers: spatially segregated fruit and pheromone representation. Cell 128:1187-1203

Jiao Y, Moon SJ, Montell C (2007) A Drosophila gustatory receptor required for the responses to sucrose glucose and maltose identified by mRNA tagging. Proc Natl Acad Sci USA 104:14110-14115

Jones WD, Cayirlioglu P, Kadow IG, Vosshall LB (2007) Two chemosensory receptors together mediate carbon dioxide detection in Drosophila. Nature 445:86-90

Kaas JH (2005) The future of mapping sensory cortex in primates: three of many remaining issues. Philos Trans R Soc Lond B 360:653-664

Kaun KR, Hendel T, Gerber B, Sokolowski MB (2007) Natural variation in Drosophila larval reward learning and memory due to a cGMP-dependent protein kinase. Learn Mem $14: 342-349$

Keene AC, Stratmann M, Keller A, Perrat PN, Vosshall LB, Waddell S (2004) Diverse odorconditioned memories require uniquely timed dorsal paired medial neuron output. Neuron 44:521-533

Keene AC, Waddell S (2007) Drosophila olfactory memory: single genes to complex neural circuits. Nat Rev Neurosci 8:341-354

Keene AC, Krashes MJ, Leung B, Bernard JA, Waddell S (2006) Drosophila dorsal paired medial neurons provide a general mechanism for memory consolidation. Curr Biol 16:1524-1530

Kim YC, Lee HG, Seong CS, Han KA (2003) Expression of a Dl dopamine receptor dDA1/ DmDOP1 in the central nervous system of Drosophila melanogaster. Gene Expr Patterns 3:237-245

Kim YC, Lee HG, Han KA (2007) D1 dopamine receptor dDA1 is required in the mushroom body neurons for aversive and appetitive learning in Drosophila. J Neurosci 27:7640-7647

Kittel RJ, Wichmann C, Rasse TM, Fouquet W, Schmidt M, Schmid A, Wagh DA, Pawlu C, Kellner RR, Willig KI, Hell SW, Buchner E, Heckmann M, Sigrist SJ (2006) Bruchpilot promotes active zone assembly, $\mathrm{Ca}^{2+}$ channel clustering, and vesicle release. Science 312:1051-1054

Klagges B, Heimbeck G, Godenschwege TA, Hofbauer A, Pflugfelder GO, Reifegerste R, Reisch D, Schaupp M, Buchner S, Buchner E (1996) Invertebrate synapsins: a single gene codes for several isoforms in Drosophila. J Neurosci 16:3154-3165

Knight D, Iliadi K, Charlton MP, Atwood HL, Boulianne GL (2007) Presynaptic plasticity and associative learning are impaired in a Drosophila presenilin null mutant. Dev Neurobiol 67:1598-1613

Kondoh Y, Kaneshiro KY, Kimura K, Yamamoto D (2003) Evolution of sexual dimorphism in the olfactory brain of Hawaiian Drosophila. Proc R Soc Lond B 270:1005-1013

Krashes MJ, Keene AC, Leung B, Armstrong JD, Waddell S (2007) Sequential use of mushroom body neuron subsets during Drosophila odor memory processing. Neuron 53:103-115

Krashes MJ, Waddell S (2008) Rapid consolidation to a radish and protein synthesis-dependent long-term memory after single-session appetitive olfactory conditioning in Drosophila. $\mathbf{J}$ Neuro Sci. 28:3103-3113

Kreher SA, Kwon AY, Carlson JR (2005) The molecular basis of odor coding in the Drosophila larva. Neuron 46:445-456

Kreher, S.A, Mathew, D, Kim, J, Carlson, JR, (2008) Translation of sensory input into behavioral output via an olfactory system. Neuron 59: 110-124

Kurtovic A, Widmer A, Dickson BJ (2007) A single class of olfactory neurons mediates behavioural responses to Drosophila sex pheromone. Nature 446:542-546 
Kwon JY, Dahanukar A, Weiss LA, Carlson JR (2007) The molecular basis of $\mathrm{CO}_{2}$ reception in Drosophila. Proc Natl Acad Sci USA 104:3574-3578

Laissue PP, Reiter C, Hiesinger PR, Halter S, Fischbach KF, Stocker RF (1999) Three-dimensional reconstruction of the antennal lobe in Drosophila melanogaster. J Comp Neurol 405:543-552

Larsson MC, Domingos AI, Jones WD, Chiappe ME, Amrein H, Vosshall LB (2004) Or83b encodes a broadly expressed odorant receptor essential for Drosophila olfaction. Neuron 43:703-714

Lacaille F, Hiroi M, Twele R, Inoshita T, Umemoto D, Manière G, Marion-Poll F, Ozaki M, Francke W, Everaerts C, Tanimura T, Ferveur J-F (2007) A inhibitory sex pheromone tastes bitter for males. PLoS ONE 2:e661

Laurent G (1996) Odor images and tunes. Neuron 16:473-476

Lee T, Lee A, Luo L (1999) Development of the Drosophila mushroom bodies: sequential generation of three distinct types of neurons from a neuroblast. Development 126:4065-4076

Levin LR, Han PL, Hwang PM, Feinstein PG, Davis RL, Reed RR (1992) The Drosophila learning and memory gene rutabaga encodes a $\mathrm{Ca}^{2+} /$ calmodulin-responsive adenylyl cyclase. Cell 68:479-489

Li J, Ashley J, Budnik V, Bhat MA (2007) Crucial role of Drosophila neurexin in proper active zone apposition to postsynaptic densities, synaptic growth, and synaptic transmission. Neuron 55:741-755

Lienhard MC, Stocker RF (1987) Sensory projection patterns of supernumerary legs and aristae in D. melanogaster. J Exp Zool 244:187-201

Lin HH, Lai JS, Chin AL, Chen YC, Chiang AS (2007) A map of olfactory representation in the Drosophila mushroom body. Cell 128:1205-1217

Lindemann B (2001) Receptors and transduction in taste. Nature 413:219-225

Liu L, Leonard AS, Motto DG, Feller MA, Price MP, Johnson WA, Welsh MJ (2003a) Contribution of Drosophila DEG/ENaC genes to salt taste. Neuron 39:133-146

Liu L, Yermolaieva O, Johnson WA, Abboud FM, Welsh MJ (2003b) Identification and function of thermosensory neurons in Drosophila larvae. Nat Neurosci 6:267-273

Liu G, Seiler H, Wen A, Zars T, Ito K, Wolf R, Heisenberg M, Liu L (2006) Distinct memory traces for two visual features in the Drosophila brain. Nature 439:551-556

Louis M, Huber T, Benton R, Sakmar TP, Vosshall LB (2008) Bilateral olfactory sensory input enhances chemotaxis behavior. Nat Neurosci 11:187-199

Manoli DS, Foss M, Villella A, Taylor BJ, Hall JC, Baker BS (2005) Male-specific fruitless specifies the neural substrates of Drosophila courtship behavior. Nature 436:395-400

Mao Z, Roman G, Zong L, Davis RL (2004) Pharmacogenetic rescue in time and space of the rutabaga memory impairment by using Gene-Switch. Proc Natl Acad Sci USA 101:198-203

Marella S, Fischler W, Kong P, Asgarian S, Rueckert E, Scott K (2006) Imaging taste responses in the fly brain reveals a functional map of taste category and behavior. Neuron 49:285-295

Margulies C, Tully T, Dubnau J (2005) Deconstructing memory in Drosophila. Curr Biol 15:R700-R713

Marin EC, Jefferis GSXE, Komiyama T, Zhu H, Luo L (2002) Representation of the glomerular olfactory map in the Drosophila brain. Cell 109:243-255

Marin EC, Watts RJ, Tanaka NK, Ito K, Luo L (2005) Developmentally programmed remodeling of the Drosophila olfactory circuit. Development 132:725-737

Masuda-Nakagawa LM, Tanaka NK, O'Kane CJ (2005) Stereotypic and random patterns of connectivity in the larval mushroom body calyx of Drosophila. Proc Natl Acad Sci USA 102:19027-19032

Matsuo T, Sugaya S, Yasukawa J, Aigaki T, Fuyama Y (2007) Odorant-binding proteins OBP57d and OBP57e affect taste perception and host-plant preference in Drosophila sechellia. PLoS Biol 5:e118

McGuire SE, Le PT, Davis RL (2001) The role of Drosophila mushroom body signaling in olfactory memory. Science 293:1330-1333

McGuire SE, Le PT, Osborn AJ, Matsumoto K, Davis RL (2003) Spatiotemporal rescue of memory dysfunction in Drosophila. Science 302:1765-1768

McGuire SE, Deshazer M, Davis RL (2005) Thirty years of olfactory learning and memory research in Drosophila melanogaster. Prog Neurobiol 76:328-347 
Melcher C, Pankratz MJ (2005) Candidate gustatory interneurons modulating feeding behavior in the Drosophila brain. PLoS Biol 3:e305

Meunier N, Ferveur JF, Marion-Poll F (2000) Sex-specific non-pheromonal taste receptors in Drosophila. Curr Biol 10:1583-1586

Meunier N, Marion-Poll F, Rospars JP, Tanimura T (2003) Peripheral coding of bitter taste in Drosophila. J Neurobiol 56:139-152

Miyakawa Y (1982) Behavioral evidence for the existence of sugar, salt and amino acid recptor cells and some of their properties in Drosophila larvae. J Insect Physiol 28:405-410

Michels B, Diegelmann S, Tanimoto H, Schwenkert I, Buchner E, Gerber B (2005) A role of synapsin for associative learning: The Drosophila larva as a study case. Learn Mem 12:224-231

Mombaerts P, Wang F, Dulac C, Chao SK, Nemes A, Mendelsohn M, Edmondson J, Axel R (1996) Visualizing an olfactory sensory map. Cell 87:675-686

Moon SJ, Kottgen M, Jiao Y, Xu H, Montell C (2006) A taste receptor required for the caffeine response in vivo. Curr Biol 16:1812-1817

Murthy M, Fiete I, Laurent G (2008) Testing odor response stereotypy in the Drosophila mushroom body. Neuron 59:1009-1023

Nayak SV, Singh RN (1983) Sensilla on the tarsal segments and mouthparts of adult Drosophila melanogaster Meigen (Diptera Drosophilidae). Int J Insect Morphol Embryol 12:273-291

Neuser K, Husse J, Stock P, Gerber B (2005) Appetitive olfactory learning in Drosophila larvae: effects of repetition, reward strength, age, gender, assay type, and memory span. Anim Behav 69:891-898

Ng M, Roorda RD, Lima SQ, Zemelman BV, Morcillo P, Miesenböck G (2002) Transmission of olfactory information between three populations of neurons in the antennal lobe of the fly. Neuron 36:463-474

Niewalda T, Singhal N, Fiala A, Saumweber T, Wegener S, Gerber B (2008) Salt processing in larval Drosophila: Choice, feeding, and learning shift from appetitive to aversive in a concentration-dependent way. Chem Senses 33:685-692

Olsen SR, Bhandawat V, Wilson RI (2007) Excitatory interactions between olfactory processing channels in the Drosophila antennal lobe. Neuron 54:89-103

Osborne KA, Robicho A, Burgess E, Butland S, Shaw RA, Coulthard A, Pereira HS, Greenspan RJ, Sokolowski MB (1997) Natural behavior polymorphism due to a cGMP-dependent protein kinase of Drosophila. Science 277:834-836

Ozaki M, Wada-Katsumata A, Fujikawa K, Iwasaki M, Yokohari F, Satoji Y, Nisimura T, Yamaoka $\mathrm{R}$ (2005) Ant nestmate and non-nestmate discrimination by a chemosensory sensillum. Science 309:311-314

Park SK, Mann KJ, Lin H, Starostina E, Kolski-Andreaco A, Pikielny CW (2006) A Drosophila protein specific to pheromone-sensing gustatory hairs delays males' copulation attempts. Curr Biol 16:1154-1159

Peele P, Ditzen M, Menzel R, Galizia CG (2006) Appetitive odor learning does not change olfactory coding in a subpopulation of honeybee antennal lobe neurons. J Comp Physiol A Neuroethol Sens Neural Behav Physiol [A] 192:1083-1103

Pelz D, Roeske T, Syed Z, de Bruyne M, Galizia CG (2006) The molecular receptive range of an olfactory receptor in vivo (Drosophila melanogaster Or22a). J Neurobiol 66:1544-1563

Perez-Orive J, Mazor O, Turner GC, Cassenaer S, Wilson RI, Laurent G (2002) Oscillations and sparsening of odor representations in the mushroom body. Science 297:359-365

Perisse E, Portelli G, Le Goas S, Teste E, Le Bourg E (2007) Further characterization of an aversive learning task in Drosophila melanogaster: intensity of the stimulus, relearning, and use of rutabaga mutants. J Comp Physiol A Neuroethol Sens Neural Behav Physiol 193:1139-1149

Python F, Stocker RF (2002) Adult-like complexity of the larval antennal lobe of D. melanogaster despite markedly low numbers of odorant receptor neurons. J Comp Neurol 445:374-387

Quinn WG, Harris WA, Benzer S (1974) Conditioned behavior in Drosophila melanogaster. Proc Natl Acad Sci USA 71:708-712

Ramaekers A, Magnenat E, Marin EC, Gendre N, Jefferis GSXE, Luo L, Stocker RF (2005) Glomerular maps without cellular redundancy at successive levels of the Drosophila larval olfactory circuit. Curr Biol 15:982-992 
Ressler KJ, Sullivan SL, Buck LB (1994) Information coding in the olfactory system: Evidence for a stereotyped and highly organized epitope map in the olfactory bulb. Cell 79:1245-1255

Riemensperger T, Voller T, Stock P, Buchner E, Fiala A (2005) Punishment prediction by dopaminergic neurons in Drosophila. Curr Biol 15:1953-1960

Robertson HM, Warr CG, Carlson JR (2003) Molecular evolution of the insect chemoreceptor gene superfamily in Drosophila melanogaster. Proc Natl Acad Sci USA 100:14537-14542

Rodrigues V (1980) Olfactory behavior of Drosophila melanogaster. In: Siddiqi O, Babu P, Hall LM, Hall JC (eds) Development and Neurobiology of Drosophila. New York, London: Plenum, pp 361-371

Rodrigues V, Siddiqi O (1978) Genetic-analysis of chemosensory pathway. Proc Indian Acad Sci Sect B Biol Sci 87:147-160

Root CM, Semmelhack JL, Wong AM, Flores J, Wang JW (2007) Propagation of olfactory information in Drosophila. Proc Natl Acad Sci USA 104:11826-11831

Sachse S, Rueckert E, Keller A, Okada R, Tanaka NK, Ito K, and Vosshall L.B. (2007). Activity-dependent plasticity in an olfactory circuit. Neuron $56,838-850$

Sato K, Pellegrino M, Nakagawa T, Vosshall LB, Touhara K (2008) Insect olfactory receptors are heteromeric ligand-gated ion channels. Nature 452:1002-1006.

Scherer S, Stocker RF, Gerber B (2003) Olfactory learning in individually assayed Drosophila larvae. Learn Mem 10:217-225

Schipanski A (2007) Reinforcement processing in larval Drosophila melanogaster. Diploma Thesis, University of Würzburg

Schipanski A, Yarali A, Niewalda T, Gerber B (2008) Behavioral analyses of sugar processing in choice, feeding, and learning in larval Drosophila. Chem Senses 33:563-573

Schroll C, Riemensperger T, Bucher D, Ehmer J, Völler T, Erbgut K, Gerber B, Hendel T, Nagel G, Buchner E, Fiala A (2006) Light-induced activation of distinct modulatory neurons substitutes for appetitive or aversive reinforcement during associative learning in larval Drosophila. Curr Biol 16:1741-1747

Schlief, M.L., and Wilson, R.I. (2007). Olfactory processing and behavior downstream from highly selective receptor neurons. Nat Neurosci 10, 623-630

Schwaerzel M, Heisenberg M, Zars T (2002) Extinction antagonizes olfactory memory at the subcellular level. Neuron 35:951-960

Schwaerzel M (2003) Localizing engrams of olfactory memories in Drosophila. PhD Thesis, University of Würzburg

Schwaerzel M, Monastirioti M, Scholz H, Friggi-Grelin F, Birman S, Heisenberg M (2003) Dopamine and octopamine differentiate between aversive and appetitive olfactory memories in Drosophila. J Neurosci 23:10495-10502

Schwaerzel M, Jaeckel A, Mueller U (2007) Signaling at A-kinase anchoring proteins organizes anesthesia-sensitive memory in Drosophila. J Neurosci 27:1229-1233

Scott K, Brady R Jr, Cravchik A, Morozov P, Rzhetsky A, Zuker C, Axel R (2001) A chemosensory gene family encoding candidate gustatory and olfactory receptors in Drosophila. Cell 104:661-673

Shanbhag SR, Müller B, Steinbrecht RA (1999) Atlas of olfactory organs of Drosophila melanogaster. 1. Types, external organization, innervation and distribution of olfactory sensilla. Int J Insect Morphol Embryol 28:377-397

Shanbhag SR, Park SK, Pikielny CW, Steinbrecht RA (2001) Gustatory organs of Drosophila melanogaster fine structure and expression of the putative odorant-binding protein PBPRP2. Cell Tissue Res 304:423-437

Shang Y, Claridge-Chang A, Sjulson L, Pypaert M, Miesenböck G (2007) Excitatory local circuits and their implications for olfactory processing in the fly antennal lobe. Cell 128:601-612

Sinakevitch I, Strausfeld NJ (2006) Comparison of octopamine-like immunoreactivity in the brains of the fruit fly and blow fly. J Comp Neurol 494:460-475

Singh RN (1998) Neurobiology of the gustatory systems of Drosophila and some terrestrial insects. Microsc Res Techn 39:547-563

Singh RN, Singh K (1984) Fine structure of the sensory organs of Drosophila melanogaster Meigen larva (Diptera: Drosophilidae). Int J Insect Morphol Embryol 13:255-273 
Slone J, Daniels J, Amrein H (2007) Sugar receptors in Drosophila. Curr Biol 17:1809-1816

Sone M, Suzuki E, Hoshino M, Hou D, Kuromi H, Fukata M, Kuroda S, Kaibuchi K, Nabeshima Y, Hama C (2000) Synaptic development is controlled in the periactive zones of Drosophila synapses. Development 127:4157-4168

Stocker RF (1994) The organization of the chemosensory system in Drosophila melanogaster: a review. Cell Tiss Res 275:3-26

Stocker RF (2001) Drosophila as a focus in olfactory research: mapping of olfactory sensilla by fine structure, odor specificity, odorant receptor expression and central connectivity. Microsc Res Techn 55:284-296

Stocker RF, Heimbeck G, Gendre N, de Belle JS (1997) Neuroblast ablation in Drosophila P[GAL4] lines reveals origins of olfactory interneurons. J Neurobiol 32:443-456

Stocker RF, Singh RN, Schorderet M, Siddiqi O (1983) Projection patterns of different types of antennal sensilla in the antennal glomeruli of Drosophila melanogaster. Cell Tissue Res 232:237-248

Stockinger P, Kvitsiani D, Rotkopf S, Tirian L, Dickson BJ (2005) Neural circuitry that governs Drosophila male courtship behavior. Cell 121:795-807

Strausfeld NJ, Hildebrand JG (1999) Olfactory systems: common design, uncommon origins? Curr Opin Neurobiol 9:634-639

Strausfeld NJ, Sinakevitch I, Vilinsky I (2003) The mushroom bodies of Drosophila melanogaster: an immunocytological and Golgi study of Kenyon cell organization in the calyces and lobes. Microsc Res Tech 62:151-169

Suh GSB, Wong AM, Hergarden AC, Wang JW, Simon AF, Benzer S, Axel R, Anderson DJ (2004) A single population of olfactory sensory neurons mediates an innate avoidance behavior in Drosophila. Nature 431:854-859

Tamura T, Chiang AS, Ito N, Liu HP, Horiuchi J, Tully T, Saitoe M (2003) Aging specifically impairs amnesiac-dependent memory in Drosophila. Neuron 40:1003-1011

Tanaka NK, Awasaki T, Shimada T, Ito K (2004) Integration of chemosensory pathways in the Drosophila second-order olfactory centers. Curr Biol 14:449-457

Tanaka NK, Tanimoto H, and Ito, K (2008). Neuronal assemblies of the Drosophila mushroom body. J Comp Neurol 508, 711-755

Tanimura T, Isono K, Takamura T, Shimada I (1982) Genetic dimorphism in the taste sensitivity to trehalose in Drosophila melanogaster. J Comp Physiol [A] 147:433-437

Tanimura T, Isono K, Yamamoto M-T (1988) Taste sensitivity to trehalose and its alteration by gene dosage in Drosophila melanogaster. Genetics 119:366-406

Tempel BL, Bonini N, Dawson DR, Quinn WG (1983) Reward learning in normal and mutant Drosophila. Proc Natl Acad Sci USA 80:1482-1486

Thorne N, Chromey C, Bray S, Amrein H (2004) Taste perception and coding in Drosophila. Curr Biol 14:1065-1079

Thum AS, Jenett A, Ito K, Heisenberg M, Tanimoto H (2007) Multiple memory traces for olfactory reward learning in Drosophila. J Neurosci 27:11132-11138

Tully T, Quinn WG (1985) Classical conditioning and retention in normal and mutant Drosophila melanogaster. J Comp Physiol [A] 157:263-277

Tully T, Cambiazo V, Kruse L (1994) Memory through metamorphosis in normal and mutant Drosophila. J Neurosci 14:68-74

Ueno K, Ohta M, Morita H, Mikuni Y, Nakajima S, Yamamoto K, Isono K (2001) Trehalose sensitivity in Drosophila correlates with mutations in and expression of the gustatory receptor gene Gr5a. Curr Biol 11:1451-1455

Van der Goes van Naters W, Carlson JR (2007) Receptors and neurons for fly odors in Drosophila. Curr Biol 17:606-612

Vassar R, Chao SK, Sitcheran R, Nunez JM, Vosshall LB, Axel R (1994) Topographic organization of sensory projections to the olfactory bulb. Cell 79:981-991

Vosshall LB, Amrein H, Morozov PS, Rzhetsky A, Axel R (1999) A spatial map of olfactory receptor expression in the Drosophila antenna. Cell 96:725-736

Vosshall LB, Wong AM, Axel R (2000) An olfactory sensory map in the fly brain. Cell 102:147-159. 
Vosshall LB, Stocker RF (2007) Molecular architecture of smell and taste in Drosophila. Annu Rev Neurosci 30:505-533

Waddell S, Armstrong JD, Kitamoto T, Kaiser K, Quinn WG (2000) The amnesiac gene product is expressed in two neurons in the Drosophila brain that are critical for memory. Cell 103:805-813

Wagh DA, Rasse TM, Asan E, Hofbauer A, Schwenkert I, Durrbeck H, Buchner S, Dabauvalle MC, Schmidt M, Qin G, Wichmann C, Kittel R, Sigrist SJ, Buchner E (2006) Bruchpilot, a protein with homology to ELKS/CAST, is required for structural integrity and function of synaptic active zones in Drosophila. Neuron 49:833-844

Wang Y, Guo HF, Pologruto TA, Hannan F, Hakker I, Svoboda K, Zhong Y (2004a) Stereotyped odor-evoked activity in the mushroom body of Drosophila revealed by green fluorescent proteinbased $\mathrm{Ca}^{2+}$ imaging. J Neurosci 24:6507-6514

Wang Z, Singhvi A, Kong P, Scott K (2004b) Taste representations in the Drosophila brain. Cell 117:981-991

Wicher D, Schafer R, Bauernfeind R, Stensmyr MC, Heller R, Heinemann SH, Hansson BS (2008) Drosophila odorant receptors are both ligand-gated and cyclic-nucleotide-activated cation channels. Nature 452:1007-1011

Wilson RI, Laurent G (2005) Role of GABAergic inhibition in shaping odor-evoked spatiotemporal patterns in the Drosophila antennal lobe. J Neurosci 25:9069-9079

Wilson RI, Turner GC, Laurent G (2004) Transformation of olfactory representations in the Drosophila antennal lobe. Science 303:366-370

Wolfe MS (2007) When loss is gain: reduced presenilin proteolytic function leads to increased Abeta42/Abeta40. Talking point on the role of presenilin mutations in Alzheimer disease. EMBO Rep 8:136-140

Wong AM, Wang JW, Axel R (2002) Spatial representation of the glomerular map in the Drosophila protocerebrum. Cell 109:229-241

Wustmann G, Rein K, Wolf R, Heisenberg M (1996) A new paradigm for operant conditioning of Drosophila melanogaster. J Comp Physiol [A] 179:429-436

Yao CA, Ignell R, Carlson JR (2005) Chemosensory coding by neurons in the coeloconic sensilla of the Drosophila antenna. J Neurosci 25:8359-8367

Yarali T, Hendel B, Gerber B (2007) Olfactory learning and behaviour are 'insulated' against visual processing in larval Drosophila. J Comp Physiol [A] 192:1133-1145

Yasuyama K, Meinertzhagen IA, Schürmann FW (2002) Synaptic organization of the mushroom body calyx in Drosophila melanogaster. J Comp Neurol 445:211-226

Yu D, Ponomarev A, Davis RL (2004) Altered representation of the spatial code for odors after olfactory classical conditioning: memory trace formation by synaptic recruitment. Neuron $42: 437-449$

Yu D, Keene AC, Srivatsan A, Waddell S, Davis RL (2005) Drosophila DPM neurons form a delayed and branch-specific memory trace after olfactory classical conditioning. Cell 123:945-957

Zars T (2000) Behavioral functions of the insect mushroom bodies. Curr Opin Neurobiol 10:790-795

Zars T, Fischer M, Schulz R, Heisenberg M (2000) Localization of a short-term memory in Drosophila. Science 288:672-675

Zeng X, Sun M, Liu L, Chen F, Wei L, Xie W (2007) Neurexin-1 is required for synapse formation and larvae associative learning in Drosophila. FEBS Lett 581:2509-25169 